Article

\title{
Supercritical synthesis of platinum-modified titanium dioxide for solar fuel production from carbon dioxide
}

\author{
Susana Tostón, Rafael Camarillo*, Fabiola Martínez, Carlos Jiménez, Jesusa Rincón \\ University of Castilla-La Mancha, Department of Chemical Engineering, Faculty of Environmental Sciences and Biochemistry, Avda. Carlos III, s/n, 45071 \\ Toledo, Spain
}

A R T I C L E I N F O

Article history:

Received 21 November 2016

Accepted 21 December 2016

Published 5 April 2017

\section{Keywords:}

Titanium dioxide

Platinum

Photocatalyst

Metal dispersion

Carbon dioxide photoreduction

\begin{abstract}
A B S T R A C T
This paper investigates the properties of $\mathrm{TiO}_{2}$-based photocatalysts synthesised under supercritical conditions. Specifically, the characteristics of Pt dispersed on $\mathrm{TiO}_{2}$ catalysts obtained in supercritical $\mathrm{CO}_{2}$ are discussed and compared with those of commercial $\mathrm{TiO}_{2}$. The photocatalytic activity of the synthesised catalysts in the $\mathrm{CO}_{2}$ photoreduction reaction to produce solar fuel is tested. The main conclusion of the study is that photocatalysts with better or similar features, including high surface area, crystallisation degree, hydroxyl surface concentration, pore volume, absorbance in the visible range and methane production rate, to those of commercial $\mathrm{TiO}_{2}$ may be produced for the reduction of $\mathrm{CO}_{2}$ to fuel by synthesis in supercritical media.
\end{abstract}

(C) 2017, Dalian Institute of Chemical Physics, Chinese Academy of Sciences. Published by Elsevier B.V. All rights reserved.

\section{Introduction}

The increasing atmospheric concentration of greenhouse gases, especially $\mathrm{CO}_{2}$, is a pressing social issue at present [1]. Different processes to capture gas from large point sources such as the flue gases of coal, oil, natural gas and biomass power plants have been patented in recent years [2,3]. The recovered $\mathrm{CO}_{2}$ can be either stored in natural caves or used as feedstock to produce useful chemicals, especially fuel, which is the only $\mathrm{CO}_{2}$ conversion product that may substantially lower anthropogenic $\mathrm{CO}_{2}$ emissions because of its high rate of consumption. However, because the $\mathrm{CO}_{2}$ molecule is very stable, only a few technologies for its conversion are available. In particular, effective photocatalytic conversion of $\mathrm{CO}_{2}$ to fuel has been demonstrated $[4,5]$. Thus, following this previous work, the present study focuses on the synthesis of catalysts for the photocatalytic conversion of $\mathrm{CO}_{2}$ gas into fuel using solar energy (i.e., catalysts for solar fuel production from $\mathrm{CO}_{2}$ ), a process with an enormous future potential despite being in the early stages of development.

The main drawbacks currently limiting photocatalytic $\mathrm{CO}_{2}$ reduction are low photoconversion speed and efficiency. These problems may be overcome through the design of highly active photocatalysts with favourable reactant adsorption, charge separation and transport, light harvesting and $\mathrm{CO}_{2}$ activation [6-14]. $\mathrm{TiO}_{2}$ particles show most of these features along with non-toxicity, high photostability, chemical inertness, environmentally friendly nature and low cost. Thus, $\mathrm{TiO}_{2}$ is a promising material for use as a catalyst in $\mathrm{CO}_{2}$ photoreduction.

The main weakness of $\mathrm{TiO}_{2}$ is that it only uses the ultraviolet (UV) region of the solar spectrum, which is less than $5 \%$ of the total solar energy. Moreover, after UV irradiation of $\mathrm{TiO}_{2}$ with an energy equal or larger than its band gap $(3.2 \mathrm{eV})$, the resulting photogenerated electron-hole pairs rapidly recombine.

\footnotetext{
* Corresponding author. E-mail: rafael.camarillo@uclm.es

This work was supported by Spanish Government (Project CTM 2011-26564), Regional Government of Castilla-La Mancha (Project PEII10-0310-5840), and Iberdrola Foundation (Research Grant in Energy and the Environment 2010/12 for Susana Tostón). DOI: 10.1016/S1872-2067(17)62766-9 | http://www.sciencedirect.com/science/journal/18722067 | Chin. J. Catal., Vol. 38, No. 4, April 2017
} 
However, both problems can be tackled with appropriate dispersion or doping of $\mathrm{TiO}_{2}$ with either noble or transition metals $[7,9,10,12,15-17]$. The dispersion method leads to the scattering of metal particles on the $\mathrm{TiO}_{2}$ support, while doping involves the inclusion or substitution of foreign metal atoms into the $\mathrm{TiO}_{2}$ lattice $[10,18]$.

The most commonly ascribed effect of $\mathrm{Pt}$ as a dopant for $\mathrm{TiO}_{2}$ is its ability to promote charge carrier separation because electrons tend to accumulate on the doped $\mathrm{Pt}$ and holes remain on $\mathrm{TiO}_{2}$. Pt also shifts the band edges of $\mathrm{TiO}_{2}$ to make certain electron transfer processes more favourable in the vicinity of the metal atom. In addition, Pt increases the electron scavenging capability of $\mathrm{O}_{2}$, removes strongly bound intermediates, promotes hydroxyl $(\mathrm{OH})$ formation and promotes $\mathrm{H}^{+}$reduction to adsorbed $\mathrm{H}$ atoms [18]. However, the influence of $\mathrm{Pt}$ on $\mathrm{TiO}_{2}$ photocatalysis is not always positive because Pt atoms may act as charge recombination centres or block active sites on $\mathrm{TiO}_{2}$. Moreover, $\mathrm{Pt}$ is a good centre for hydrogen $\left(\mathrm{H}_{2}\right)$ generation from $\mathrm{H}_{2} \mathrm{O}$; therefore, it is necessary to take measures to minimise this process [19].

The amount of $\mathrm{Pt}$ added to $\mathrm{TiO}_{2}$ can also play a major role in catalyst performance. The typical optimal Pt loading is around 1 wt $\%[9,18]$. Higher metal contents can induce faster electron-hole recombination and deactivate the photocatalyst $[10,20]$. Table 1 summarises details of some recent $\mathrm{Pt} / \mathrm{TiO}_{2}$ catalysts. Pt concentration is typically in the range of $0.2-5$ wt $\%$.

Many studies have focused on how metal dispersion methods affect the photocatalytic behaviour of catalysts $[10,18]$. Several techniques have been used to disperse $\mathrm{Pt}$ atoms on $\mathrm{TiO}_{2}$ substrates [21-25,27]. One method is co-precipitation in supercritical fluids because if a metal precursor is added to a reaction medium together with a Ti precursor and a hydrolysis agent, a metal dispersed on $\mathrm{TiO}_{2}$ catalyst can be obtained in situ [28]. The use of supercritical fluids, mainly $\mathrm{CO}_{2}$ and $\mathrm{H}_{2} \mathrm{O}$, for particle generation and precipitation is attractive because of their excellent properties [29,30]-they can diffuse through solids like a gas and dissolve materials like a liquid-and their ability to be adjusted by simply changing the operating parameters [31,32]. Both the fluid properties and easy tuning of supercritical fluids allow particle characteristics such as structure, morphology, size and size distribution to be controlled. All of these characteristics are very important for the final application of a catalyst [28]. Moreover, synthesis using supercritical fluids is more environmentally sustainable than classical syn- thesis procedures, which usually use large amounts of organic solvents.

The objective of this investigation is to use a supercritical medium to synthesise a $\mathrm{TiO}_{2}$-based catalyst with superior performance to that of a commercial semiconductor in the photocatalytic reduction of $\mathrm{CO}_{2}$ to fuel molecules. Specifically, Pt dispersed on $\mathrm{TiO}_{2}$ is synthesised by a hydrothermal method using supercritical $\mathrm{CO}_{2}$. $\mathrm{Pt}(\mathrm{II})$ acetylacetonate and titanium tetraisopropoxide (TTIP) or diisopropoxy titanium bis(acetylacetonate) (DIPBAT) are used as chemical precursors of $\mathrm{Pt}$ and $\mathrm{TiO}_{2}$, respectively, with isopropyl alcohol or ethanol as a hydrolytic agent. The synthesis involves the following process. Once the reagents are in the supercritical phase, precursor decomposition occurs and alcohol decomposition provides the necessary $\mathrm{H}_{2} \mathrm{O}$ for the hydrolysis reaction $[33,34]$. The end products are Pt dispersed on $\mathrm{TiO}_{2}$ solid particles and carbonaceous contaminants originating from the precursors. The decompressed solvent is in gas phase, which facilitates catalyst drying and recovery at the end of the process. To remove carbon (C) contaminants from the catalyst, a calcination step is performed after supercritical synthesis [35].

The properties of the $\mathrm{Pt} / \mathrm{TiO}_{2}$ catalysts are determined by usual characterisation methods, including scanning electron microscopy (SEM), transmission electron microscopy (TEM), X-ray photoelectron spectroscopy (XPS), atomic emission spectroscopy with inductively coupled plasma (ICP-AES), X-ray diffraction (XRD), $\mathrm{N}_{2}$ adsorption-desorption measurements, diffuse-reflectance UV-visible (DRUV-vis) spectroscopy, Fourier transform infrared (FTIR) spectroscopy and laser diffraction, and compared with those of commercial $\mathrm{TiO}_{2}$. Their photocatalytic activity in $\mathrm{CO}_{2}$ photoreduction to produce solar fuel is also tested.

\section{Experimental}

\subsection{Chemicals}

Various samples of Pt dispersed on $\mathrm{TiO}_{2}$ powder were synthesised by thermal hydrolysis of two different precursors (DIPBAT and TTIP) with two different alcohols in the presence of $\mathrm{Pt}(\mathrm{II})$ acetylacetonate using supercritical $\mathrm{CO}_{2}$ as the reaction medium. DIPBAT (75 wt\% in isopropyl alcohol), TTIP (pure) and $\mathrm{Pt}(\mathrm{II})$ acetylacetonate (97 wt\%) were provided by Sigma-Aldrich. Analytical reagent-grade ethanol and isopropyl alcohol were provided by Scharlab. In all analyses, Degussa

Table 1

Overview of $\mathrm{Pt} / \mathrm{TiO}_{2}$-based catalysts.

\begin{tabular}{|c|c|c|c|}
\hline Support & Pt concentration (wt\%) & Method & Ref. \\
\hline $\mathrm{TiO}_{2}$ anatase & $0.5-2$ & Impregnation + air drying + calcination $\left(450^{\circ} \mathrm{C}, 4 \mathrm{~h}\right)+\mathrm{H}_{2}$ reduction & {$[21]$} \\
\hline $\mathrm{TiO}_{2}$ anatase & 5 & $\begin{array}{l}\text { Mixture of } \mathrm{TiO}_{2} \text { precursor and dopant solutions }+ \text { drying + gel grinding + calcination } \\
\qquad\left(500^{\circ} \mathrm{C}, 5 \mathrm{~h}\right)\end{array}$ & [22] \\
\hline Mesoporous $\mathrm{TiO}_{2}$ thin films & $0.5-3$ & Evaporation induced self-assembly & [23] \\
\hline $\mathrm{TiO}_{2}$ & $0.2-1$ & Sol-gel & {$[24]$} \\
\hline $\mathrm{TiO}_{2}$ & 0.15 & Sol-gel & [25] \\
\hline $\mathrm{TiO}_{2}$ & 1 & Two step hydrothermal route & [20] \\
\hline $\mathrm{TiO}_{2}$ & $0.1-0.4$ & Sol-gel & [26] \\
\hline
\end{tabular}



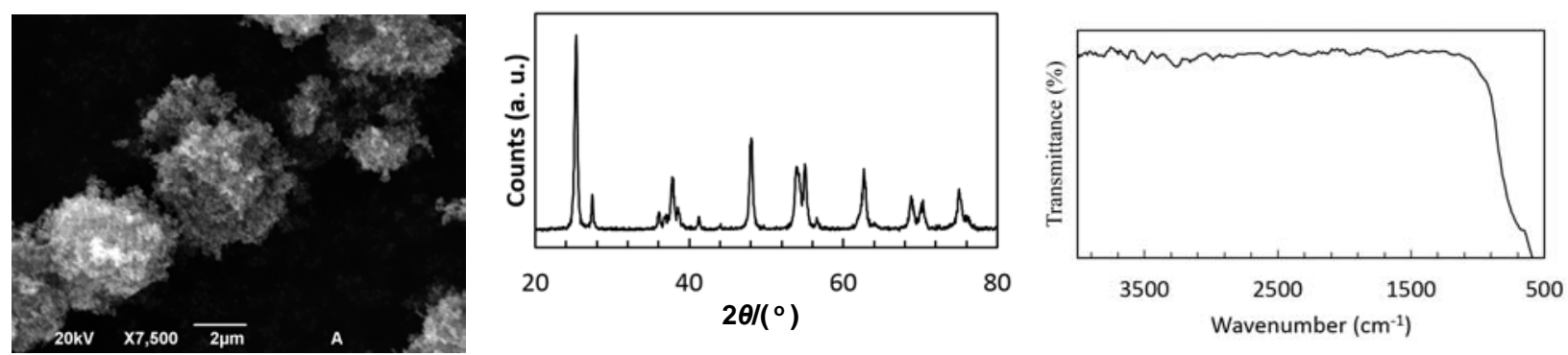

Fig. 1. SEM image (left), XRD pattern (middle) and FTIR spectrum (right) of commercial P-25 catalyst.

P-25 (Evonik) $\mathrm{TiO}_{2}$ powder was used as a reference. Some characteristics of this commercial catalyst are shown in Fig. 1 for comparison with those of the catalysts synthesised in this work. Supercritical $\mathrm{CO}_{2}$ (purity $>99.9 \%$, Carburos Metálicos S.A.) was used as received.

\subsection{Synthesis of catalysts}

The experimental set-up depicted schematically in Fig. 2 was used to synthesise photocatalysts in supercritical $\mathrm{CO}_{2}$ in discontinuous mode. The set-up consisted of a high pressure pump (Thar SFC, P-series) preceded by a thermostated bath (Selecta, Frigiterm-30) and followed by a high pressure synthesis reactor (DEMEDE Engineering \& Research, $100 \mathrm{~mL}$ ). To synthesise the catalysts, the alcohol and Ti and Pt precursors were first added to the reactor. The system was sealed and then $\mathrm{CO}_{2}$ was pumped into the reactor after being cooled in the thermostated bath. The high pressure pump and an electric resistor were used to reach and maintain the operating pressure and temperature in the reactor. After synthesis, the system was depressurised by opening valve V3 and the catalyst was collected from the reactor. Further details of this procedure are given elsewhere [34].

Catalyst synthesis was conducted at a pressure of $20 \pm 0.2$ $\mathrm{MPa}$ and temperature of $300 \pm 5{ }^{\circ} \mathrm{C}$ using a molar ratio of 28 $\mathrm{mmol}$ alcohol/mmol precursor except for in the case of the ethanol/DIPBAT combination of reactants. Given that DIPBAT is a solution in isopropyl alcohol, the molar ratio used in this case was $28 \mathrm{mmol}$ ethanol/mmol DIPBAT, although the test was actually performed in an alcohol mixture [33]. An appropriate amount of Pt(II) acetylacetonate was added to give final
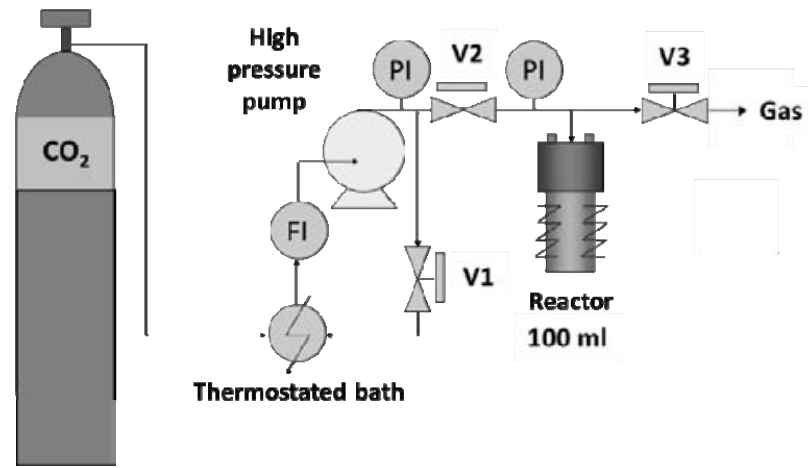

Fig. 2. Experimental system used to synthesise $\mathrm{TiO}_{2}$-based catalysts.
Pt concentrations in the range of 1-3 wt\%. Catalyst synthesis was performed for $2 \mathrm{~h}$ once the experimental conditions were reached. All syntheses were repeated three times. After the synthesised catalysts were removed from the reactor, they were dried at $105^{\circ} \mathrm{C}$ for $12 \mathrm{~h}$ and then calcined at $400{ }^{\circ} \mathrm{C}$ for $6 \mathrm{~h}$ to remove any $\mathrm{C}$ contaminants from the catalysts [35].

\subsection{Catalyst characterisation}

The $\mathrm{TiO}_{2}$-based catalysts were characterised by different techniques. The real percentage of Pt was measured by ICP-AES (Varian, Liberty Sequential). The detection limit of the ICP spectrometer was $20 \mathrm{ppb} \mathrm{Pt}$. The particle size and external morphology of the particles were observed by SEM using a scanning electron microscope (JEOL, $6490 \mathrm{LV}$ ). TEM and high-resolution TEM were measured with a JEOL 2100 TEM operating at $200 \mathrm{kV}$ equipped with a side-entry double-tilt $( \pm$ $25^{\circ}$ ) sample holder and energy-dispersive spectroscopy detector (Oxford Link). XPS was conducted using an ultrahigh-vacuum Specs Phoibos-150 electron spectrometer. The spectra were obtained with a photon energy of $1486.6 \mathrm{eV}(\mathrm{Al}$ anode). All binding energies were referenced to the $\mathrm{C} 1 \mathrm{~s}$ peak originating from surface adventitious $\mathrm{C}$ at $284.6 \mathrm{eV}$. The crystallinity and crystalline phase of the catalysts were determined by powder XRD using an X-ray diffractometer (Philips, X'Pert MPD). The crystallite sizes of the $\mathrm{TiO}_{2}$ photocatalysts were estimated via the Scherrer equation using the peak at $2 \theta=25.4^{\circ}$. The specific surface area of the powders was evaluated using a Brunauer-Emmett-Teller (BET) area analyser (Micromeritics, ASAP 2020). DRUV-vis spectra of all catalysts were obtained on a DRUV-vis spectrophotometer (JASCO, V650). Absorbance thresholds and band gap energies $(E \mathrm{~g})$ were calculated from these spectra. FTIR spectra of all samples were obtained with a FTIR attenuated total reflectance spectrometer (Thermo Nicolet, Avatar 370 FT-IR). Particle size and particle size distribution were calculated using a laser scattering particle size distribution analyser (Malvern, Mastersizer 2000).

\subsection{Photocatalytic reaction tests}

The photocatalytic activities of the catalysts in photocatalytic $\mathrm{CO}_{2}$ reduction experiments were assessed using an experimental set-up consisting of a stainless steel chamber (50 $\mathrm{cm}^{3}$ ) (Fig. 3) with valves for evacuation, gas introduction and connection to a gas chromatography (GC) system, an 


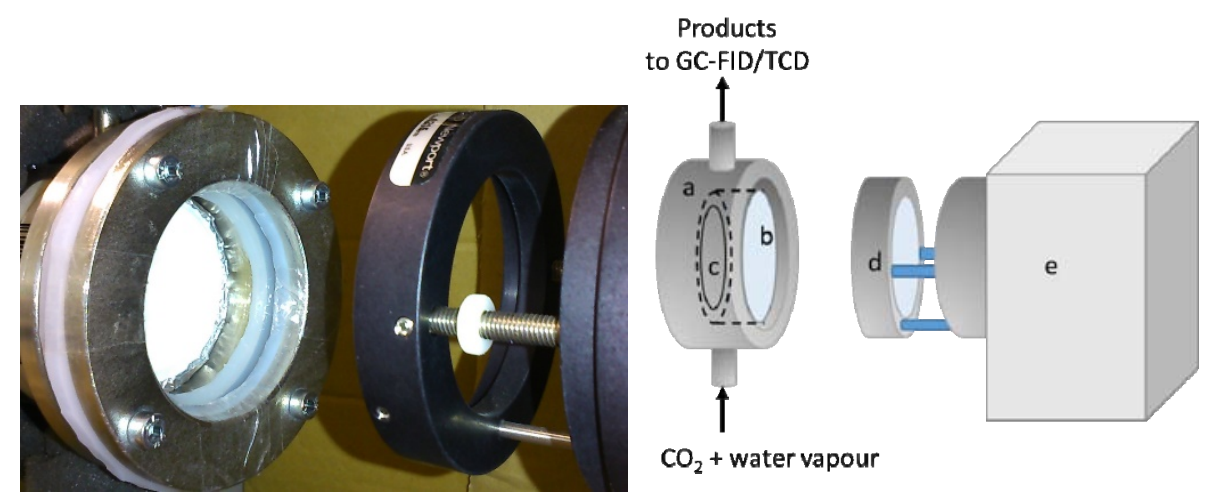

Fig. 3. Details of the photocatalytic reactor. (a) $50-\mathrm{cm}^{3}$ stainless steel chamber; (b) O-ring-sealed quartz window; (c) filter with catalyst sample; (d) Air Mass 1.5 Global filter; (e) Xe arc lamp.

O-ring-sealed quartz window at the top to admit radiation from a Xe arc lamp (Oriel, $450 \mathrm{~W}$ ) with an Air Mass 1.5 Global filter and a dew point transmitter and different manometers to measure relative humidity and pressure, respectively, during the reaction. A bubbler containing deionised $\mathrm{H}_{2} \mathrm{O}$ was positioned before the reaction chamber. The beam of the lamp was diverged with a collimator with the aim of having the inside of the reaction chamber at the same irradiance as that of the sun $\left(100 \mathrm{~mW} / \mathrm{cm}^{2}\right)$ to simulate solar radiation. It is possible that this irradiance decreased slightly with the use of the lamp, but this should have been negligible according to the manufacturer. Additional information can be found in a previous study [34].

Most experiments described in this paper were performed with a $\mathrm{H}_{2} \mathrm{O}$ vapour $/ \mathrm{CO}_{2}$ ratio of $2: 7$, although other ratios were also assessed (2:20 and 2:1). The $\mathrm{H}_{2} \mathrm{O}$ vapour/ $\mathrm{CO}_{2}$ ratio was increased by using the same amount of $\mathrm{H}_{2} \mathrm{O}$ vapour and decreasing the amount of $\mathrm{CO}_{2}$. However, to operate the photoreactor at constant pressure, appropriate quantities of an inert gas (He) were fed into the system. We operated the system in this way because if we tried to increase the $\mathrm{H}_{2} \mathrm{O}$ vapour/ $\mathrm{CO}_{2}$ ratio by increasing the partial pressure of $\mathrm{H}_{2} \mathrm{O}$ vapour while keeping the $\mathrm{CO}_{2}$ amount constant, the $\mathrm{H}_{2} \mathrm{O}$ vapour saturation pressure was reached and $\mathrm{H}_{2} \mathrm{O}$ condensed. Other variables like catalyst weight (34.6-75.5 mg) and reaction time (3-4 h) were also evaluated. The initial absolute pressure in the reactor was 1.07 bar in all experiments.

To quantitatively and qualitatively measure the different species in the reaction chamber, a GC analytical method was developed. The gas chromatograph (Agilent GC 7890A) possessed two thermal conductivity (TCD) detectors and a flame ionisation detector (FID) with a methaniser, which made it possible to determine gases such as $\mathrm{CO}, \mathrm{CO}_{2}, \mathrm{CH}_{4}$, light hydrocarbons (C1-C7), light alcohols, ethers and ketones. $\mathrm{H}_{2}$ could not be analysed in the system because of technical limitations. Specifically, because $\mathrm{He}$ was used to increase the $\mathrm{H}_{2} \mathrm{O}$ vapour $/ \mathrm{CO}_{2}$ ratio in the photocatalytic reactor, $\mathrm{H}_{2}$ and He were both present in the gas stream leaving the photoreactor. These gases could not be quantified separately because the signals for both $\mathrm{He}$ and $\mathrm{H}_{2}$ were detected in the same channel and with similar retention times. Nevertheless, according to the literature [36], in all the experiments performed in this work, the $\mathrm{H}_{2}$ produced should be negligible.
In previous experiments with Degussa-P25 conducted at a higher $\mathrm{H}_{2} \mathrm{O} / \mathrm{CO}_{2}$ ratio $\left(2 \mathrm{~g} \mathrm{H}_{2} \mathrm{O} / \mathrm{g} \mathrm{CO}_{2}\right)$ than in the present work, $\mathrm{CH}_{4}, \mathrm{CO}$ and $\mathrm{H}_{2}$ production rates were $0.025,1.233$ and 0.005 $\mu \mathrm{mol} \mathrm{g} \mathrm{g}^{-1} \mathrm{~h}^{-1}$, respectively. Therefore, the amount of $\mathrm{H}_{2}$ generated during the experiments described in the present work should be less than $0.005 \mu \mathrm{mol} \mathrm{g} \mathrm{g}^{-1} \mathrm{~h}^{-1}$.

\section{Results and discussion}

\subsection{Synthesis yield}

The yield is the ratio between the moles of catalyst produced during synthesis with supercritical $\mathrm{CO}_{2}$ and the moles of precursor used, taking into account that the synthesis reaction involves a 1:1 ratio for both precursors (1 mol precursor : 1 mol product). The yields obtained are presented in Table 2 . Reported yields are the average of triplicate experiments. The two highest yields $(85.5 \%$ and $72.0 \%)$ were achieved when TTIP was used. Furthermore, the average yield attained in the six experiments performed with TTIP was higher than the average yield of the six runs carried out with DIPBAT (66.5\% with TTIP vs. $62.4 \%$ with DIPBAT). In principle, these results could be attributed to the higher thermal and kinetic stability of DIPBAT compared with that of TTIP. TTIP is easily hydrolysable, even at ambient temperature, in the presence of humidity because it has four isopropoxy ligands coordinated to its $\mathrm{Ti}$

Table 2

Synthesis yields of different catalysts.

\begin{tabular}{lccc}
\hline Combination & $\begin{array}{c}\text { Precursor } \\
(\mathrm{mmol})\end{array}$ & $\begin{array}{c}\mathrm{TiO}_{2} \\
(\mathrm{mmol})\end{array}$ & $\begin{array}{c}\text { Yield } \\
(\%)\end{array}$ \\
\hline TTIP-isopropyl alcohol-1\%Pt & $4.889 \pm 0.003$ & $2.8 \pm 0.4$ & $57 \pm 8$ \\
TTIP-isopropyl alcohol-2\%Pt & $4.889 \pm 0.003$ & $3.1 \pm 0.4$ & $63 \pm 8$ \\
TTIP-isopropyl alcohol-3\%Pt & $4.889 \pm 0.003$ & $3.2 \pm 0.4$ & $66 \pm 8$ \\
TTIP-ethanol-1\%Pt & $4.889 \pm 0.003$ & $4.2 \pm 0.4$ & $86 \pm 8$ \\
TTIP-ethanol-2\%Pt & $4.889 \pm 0.003$ & $2.7 \pm 0.4$ & $55 \pm 8$ \\
TTIP-ethanol-3\%Pt & $4.889 \pm 0.003$ & $3.5 \pm 0.4$ & $72 \pm 8$ \\
DIPBAT-isopropyl alcohol-1\%Pt & $5.078 \pm 0.002$ & $2.9 \pm 0.4$ & $57 \pm 8$ \\
DIPBAT-isopropyl alcohol-2\%Pt & $5.078 \pm 0.002$ & $3.0 \pm 0.4$ & $59 \pm 8$ \\
DIPBAT-isopropyl alcohol-3\%Pt & $5.078 \pm 0.002$ & $3.3 \pm 0.4$ & $65 \pm 8$ \\
DIPBAT-ethanol-1\%Pt & $5.078 \pm 0.002$ & $3.1 \pm 0.4$ & $61 \pm 8$ \\
DIPBAT-ethanol-2\%Pt & $5.078 \pm 0.002$ & $3.4 \pm 0.4$ & $67 \pm 8$ \\
DIPBAT-ethanol-3\%Pt & $5.078 \pm 0.002$ & $3.5 \pm 0.4$ & $69 \pm 8$ \\
\hline
\end{tabular}


centre [33]. DIPBAT has two of these groups substituted by two acetylacetonate ligands, which are more thermally and kinetically stable than isopropoxy ligands. Thus, hydrolysis of DIPBAT is more difficult than that of TTIP but it allows better reaction control.

In contrast, synthesis experiments with ethanol as a hydrolytic agent gave slightly higher yields than those with isopropyl alcohol (71.2\% vs. $61.8 \%$ when TTIP was used as the precursor and $64.7 \%$ vs. $60.1 \%$ in the case of DIPBAT). This is probably caused by the higher polarity of ethanol than isopropyl alcohol. Alonso et al. [33] also reported that isopropyl alcohol led to a higher degree of $\mathrm{C}$ contamination in catalysts, as by-product elimination deteriorated because of their lower solubility in the less polar alcohol. For this reason, all the catalysts (even the reference commercial one) were calcined at $400{ }^{\circ} \mathrm{C}$ for $6 \mathrm{~h}$ before conducting photocatalytic experiments. The calcination temperature was limited by the transition between anatase and rutile phases, which takes place at about $700{ }^{\circ} \mathrm{C}$ [37]. This calcination step will have important consequences for the properties of the catalysts discussed below. Regarding the effect of metal loading on yields, it can be seen that this variable does not have a clear influence on the results.

\subsection{SEM, TEM, XPS and ICP-AES analyses}

The morphology of the synthesised $\mathrm{Pt} / \mathrm{TiO}_{2}$ particles after calcination is shown in Fig. 4. Spherical particles were obtained when DIPBAT was used as a precursor. The SEM images reveal these particles were well-defined spheres with diameters of about 4-5 $\mu \mathrm{m}$. These spherical particles are slightly bigger than those of commercial $\mathrm{TiO}_{2}$ (Fig. 1) and reported by Alonso et al. [33], who obtained particles with diameters of $270 \pm 125 \mathrm{~nm}$ using TTIP and $200 \pm 100 \mathrm{~nm}$ using DIPBAT under synthesis conditions similar to those in this work $\left(20 \mathrm{MPa}\right.$ and $\left.300^{\circ} \mathrm{C}\right)$. Because particle size depends on reaction temperature, the larger particles obtained here could be caused by temperature fluctuation in the reactor $\left(300 \pm 5^{\circ} \mathrm{C}\right)$; i.e., higher temperatures $\left(305^{\circ} \mathrm{C}\right)$ led to larger particles. In the case of TTIP, larger polyhedral-like particles were obtained than when using DIPBAT, especially when ethanol was used as the hydrolysis agent.
Some agglomeration was observed as the Pt loading increased, especially when ethanol was used as the hydrolysis agent. However, this phenomenon was largely avoided by calcination of the synthesised catalysts. It should also be highlighted that the particle sizes and shapes are similar to those obtained by other groups using supercritical fluid synthesis [33,38] and classical methods like chemical vapour deposition [39].

Regarding the effect of particle size and morphology on catalyst performance, a previous study [40] showed that photocatalytic activity tended to decrease with increasing particle size because specific surface area was lowered. Likewise, it has been demonstrated that anatase nanoparticles with polyhedral-like shapes are more active than those with rounded or spherical shapes [41].

Representative TEM images of TTIP-isopropyl alcohol-1\%Pt and TTIP-isopropyl alcohol-3\%Pt samples are provided in Fig. 5. In both cases, small Pt particles were uniformly dispersed over the crystalline $\mathrm{TiO}_{2}$ particles. The size distribution of $\mathrm{Pt}$ is relatively narrow for both catalysts, with average particle diameters of $2.2 \mathrm{~nm}$ for the sample with $1 \% \mathrm{Pt}$ and $3.5 \mathrm{~nm}$ for that with $3 \% \mathrm{Pt}$. This size range is consistent with that reported by Semlali et al. [23] for mesoporous $\mathrm{Pt} / \mathrm{TiO}_{2}$ thin films synthesised by evaporation-induced self-assembly with Pt loadings of 0.5-3 wt\%.

The Pt concentration of the samples was measured by ICP-AES. In all cases, the total amount of Pt was incorporated into the final product during the synthesis of the $\mathrm{Pt} / \mathrm{TiO}_{2}$ catalyst within the interval assayed (1-3 wt $\% \mathrm{Pt})$.

With respect to XPS analyses, Fig. 6 shows the XPS survey spectrum of TTIP-ethanol-1\%Pt. The sample contains Ti, O, C and $\mathrm{Pt}$, with sharp photoelectron peaks appearing at binding energies of $458.4 \mathrm{eV}$ (Ti $2 p$ ), $529.6 \mathrm{eV}$ (O 1s), $284.6 \mathrm{eV}$ (C 1s) and $68-78 \mathrm{eV}(\mathrm{Pt} 4 f)$. The Ti $2 p$ and $01 s$ peaks originated from $\mathrm{TiO}_{2}$.

The estimated ratio between the Pt $4 f$ and Ti $3 s$ peak intensities at $61.8 \mathrm{eV}$ leads to a relative Pt:Ti concentration of $0.6 \%$ on the $\mathrm{TiO}_{2}$ surface, which is compatible with the expected stoichiometry in the final product (taking into account the error when predicting stoichiometry from XPS data).

The $\mathrm{C}$ peak is attributed to the residual $\mathrm{C}$ in the sample. The
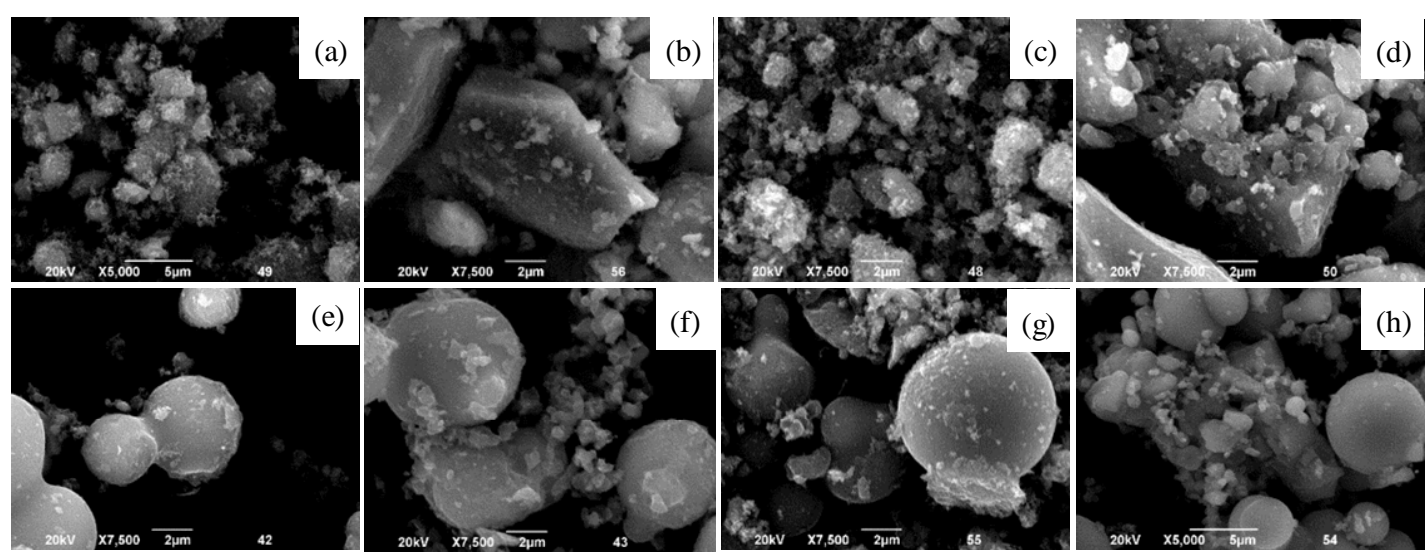

Fig. 4. SEM images of synthesised catalysts after calcination. (a) TTIP-isopropyl alcohol-1\%Pt; (b) TTIP-ethanol-1\%Pt; (c) TTIP-isopropyl alcohol-3\%Pt; (d) TTIP-ethanol-3\%Pt; (e) DIPBAT-isopropyl alcohol-1\%Pt; (f) DIPBAT-ethanol-1\%Pt; (g) DIPBAT-isopropyl alcohol-3\%Pt; (h) DIPBAT-ethanol-3\%Pt. 

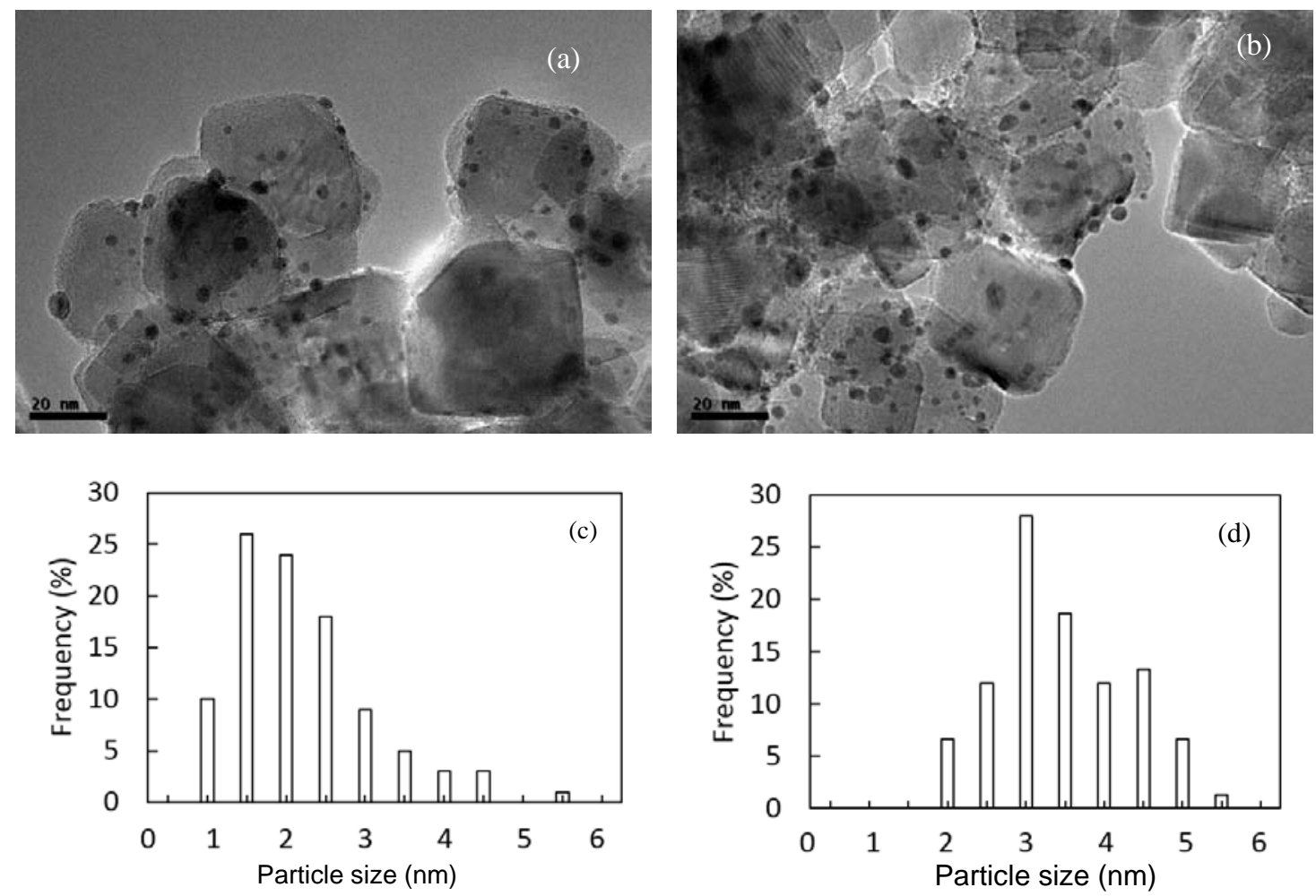

Fig. 5. Representative TEM images $(\mathrm{a}, \mathrm{b})$ and relative estimated Pt particle size distributions $(\mathrm{c}, \mathrm{d})$ of $\mathrm{Pt} / \mathrm{TiO}_{2}$ catalysts. (a,c) TTIP-isopropyl alcohol-1\%Pt; (b,d) TTIP-isopropyl alcohol-3\%Pt.

low intensity of this peak is indicative of the ready ability of the calcination process to remove precursor and alcohol C-based waste species. This peak could also arise from adventitious hydrocarbons originating from the XPS instrument itself [42].

The results of SEM, TEM, XPS and ICP-AES indicate that, from the viewpoint of morphology, the catalysts with higher photocatalytic activity will be those obtained from the TTIP-ethanol-Pt reactant combination, because they have polyhedral shapes. However, focusing on particle size, catalysts synthesised from the TTIP-isopropyl alcohol-Pt combination may also display high catalytic activity.

\subsection{XRD analysis}

XRD is a unique method to determine the crystallinity of a

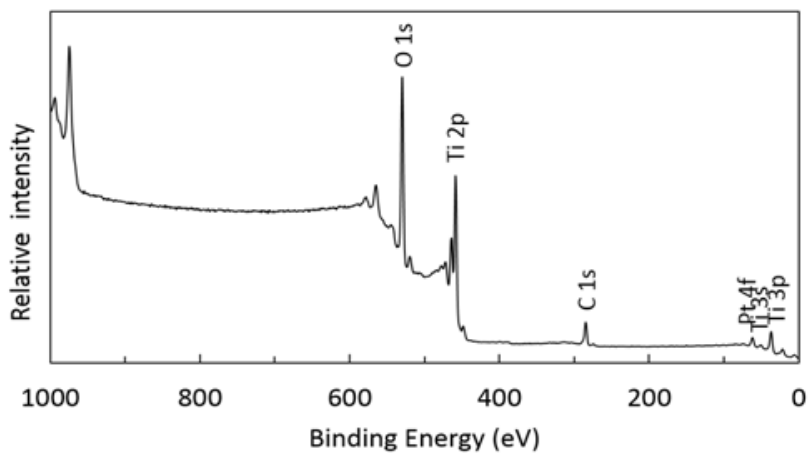

Fig. 6. XPS survey spectrum of the TTIP-ethanol-1\%Pt catalyst. compound. Knowledge about the crystallinity of a catalyst is relevant because photocatalytic performance usually increases with crystallinity, which is usually attributed to the removal of dangling bonds and distorted lattice structure acting as recombination sites as crystallinity increases. Nevertheless, high crystallinity may also lead to decreases of surface $\mathrm{OH}$ coverage and total surface area and, as a consequence, poorer catalytic behaviour [18].

XRD patterns of the catalysts obtained from the different precursor-alcohol combinations are presented in Fig. 7. The TTIP-isopropyl alcohol-Pt catalysts show the highest crystallinity (highest peak height and resolution) of the sample, very close to that of the commercial catalyst (Fig. 1). In contrast, catalysts from the other combinations exhibit poorer crystallinity, even after calcination, which usually enhances this parameter [35]. Additionally, the loading percentage of Pt does not seem to markedly affect the crystallinity of the catalysts.

Regarding crystal phase, anatase $\mathrm{TiO}_{2}$ displays diffraction peaks at $2 \theta$ of $25.4^{\circ}, 37.8^{\circ}, 48.5^{\circ}, 54.0^{\circ}, 55.4^{\circ}, 62.9^{\circ}, 68.9^{\circ}, 70.3^{\circ}$ and $75.2^{\circ}[43,44]$. According to the patterns in Fig. 7, this allotropic phase (anatase) is the most common in the catalysts synthesised in this work. In fact, no diffraction peaks originating from any other crystal phase of $\mathrm{TiO}_{2}$ were observed in the XRD patterns of synthesised catalysts, indicating the formation of pure anatase $\mathrm{TiO}_{2}$. Considering the crystal phase of the catalysts before calcination, only the anatase phase was detected, as was the case in a similar study [33] with the same reagents and under the same synthesis conditions (20 $\mathrm{MPa}$ and $300{ }^{\circ} \mathrm{C}$ ). 

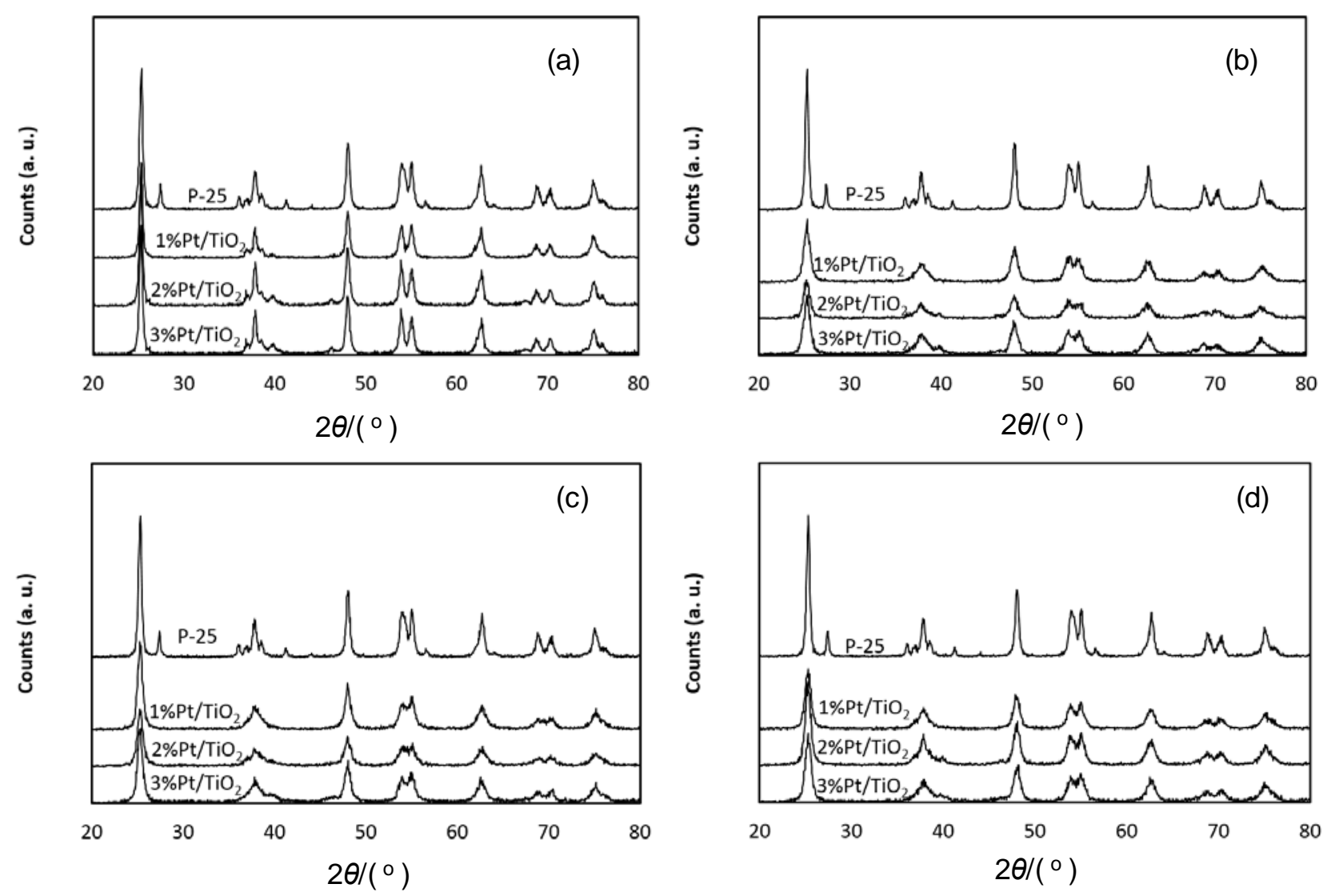

Fig. 7. XRD patterns of synthesised catalysts. (a) TTIP-isopropyl alcohol-Pt; (b) TTIP-ethanol-Pt; (c) DIPBAT-isopropyl alcohol-Pt; (d) DIPBAT-ethanol-Pt.

Metal loading does not affect the resulting crystal phase, because similar catalysts obtained in the absence of metal show only the anatase phase in their XRD patterns [45]. However, this was not the case for the commercial catalyst, because $\mathrm{TiO}_{2}$ P-25 from Evonik (formerly Degussa) is a mixture of $80 \%$ anatase and $20 \%$ rutile phases [46]. In this case, additional peaks at $27.5^{\circ}, 36.9^{\circ}$ and $41.4^{\circ}$ ascribed to rutile $\mathrm{TiO}_{2}$ are observed (Fig. 1). The absence of the rutile phase in the synthesised catalysts also means that the calcination to remove all organic contaminants is conducted at an appropriate temperature that avoids phase change [47].

This result is important because anatase $\mathrm{TiO}_{2}$ is inherently more photoactive than rutile as a result of both its solid-state properties (better light absorption and charge transport) and surface properties (larger response to charge trapping and transfer and superior chemical response to the adsorbates involved in electron transfer reactions) [18]. Fig. 7 does not contain any peaks attributable to Pt, which may be caused by the low content and high dispersity of the loaded Pt atoms [44].

Crystallite size $(D)$ is a measure of single-crystal size, and therefore it can be interpreted as an indicator of the crystalline quality of catalyst particles. This crystal parameter has the largest effect on photocatalysis from the viewpoint of light-material interactions including photon absorption, charge-carrier generation and dynamics, and surface trapping [37]. $D$, which is the size of particles in the direction vertical to the corresponding lattice plane, can be determined from XRD line broadening measurements using the Scherrer equation [48]:

$$
D \approx 0.9 \lambda / \beta \cos \theta
$$

in this equation, $\lambda$ is the X-ray wavelength $(0.1541 \mathrm{~nm}), \beta$ the full width at half-maximum intensity (rad) and $\theta$ is half of the diffraction peak angle (approximately $12.7^{\circ}$ for the $<101>$ anatase crystal facet).

Comparison of the data in Table 3 shows that the synthesised catalysts are smaller than the commercial catalyst $(19.97$ $\mathrm{nm}$ ) with the sole exception of the TTIP-isopropyl alcohol-Pt combination $(D=21.25-22.77 \mathrm{~nm})$. The smallest catalyst is TTIP-ethanol-Pt (9.65-9.98 nm). All D values reported here are compatible with those found by other groups $[38,49]$. It should also be highlighted that, according to Table 3 , the smaller particles generally have higher surface areas, although this relationship does not hold for the combination DIPBAT-ethanol-Pt. This discrepancy may be because the Scherrer equation is not completely adequate to estimate $D$ of catalysts, despite being the most popular method for this purpose. That is, when using the Scherrer equation to calculate $D$ from XRD data, $D$ are assumed to be those of a coherently diffracting domain, which is not necessarily the same as particle size. The Scherrer equation attributes XRD peak broadening exclusively to crystal size, and does not take into account that crystalline defects also cause line broadening. 
Table 3

Surface properties and crystallite sizes of commercial and synthesised catalysts.

\begin{tabular}{lcccc}
\hline Catalyst & $\begin{array}{c}D \\
(\mathrm{~nm})\end{array}$ & $\begin{array}{c}S_{\mathrm{BET}} \\
\left(\mathrm{m}^{2} / \mathrm{g}\right)\end{array}$ & $\begin{array}{r}\text { Pore } \\
\text { volume } \\
\left(\mathrm{cm}^{3} / \mathrm{g}\right)\end{array}$ & $\begin{array}{c}\text { Mean pore } \\
\text { size } \\
(\mathrm{nm})\end{array}$ \\
\hline P-25 & 20 & 63 & 0.39 & 12.5 \\
TTIP-isopropyl alcohol-1\%Pt & 23 & 51 & 0.22 & 9.5 \\
TTIP-isopropyl alcohol-2\%Pt & 21 & & & \\
TTIP-isopropyl alcohol-3\%Pt & 21 & & & \\
TTIP-ethanol-1\%Pt & 10 & 140 & 0.48 & 7.0 \\
TTIP-ethanol-2\%Pt & 10 & & & \\
TTIP-ethanol-3\%Pt & 10 & & & 6.6 \\
DIPBAT-isopropyl alcohol-1\%Pt & 13 & 140 & 0.46 & \\
DIPBAT-isopropyl alcohol-2\%Pt & 11 & & & \\
DIPBAT-isopropyl alcohol-3\%Pt & 11 & & & \\
DIPBAT-ethanol-1\%Pt & 11 & 96 & 0.40 & \\
DIPBAT-ethanol-2\%Pt & 11 & & & \\
DIPBAT-ethanol-3\%Pt & 11 & & & \\
\hline
\end{tabular}

Neither the Ti precursor nor the percentage of Pt loading strongly influenced $D$ when ethanol was used as the hydrolytic agent. In contrast, the catalysts synthesised with isopropyl alcohol displayed $D$ that depended on the precursor; larger D was obtained with TTIP than with DIPBAT. Likewise, neither the alcohol type nor the Pt loading affected $D$ when DIPBAT was used as the Ti precursor. In contrast, when TTIP was used, $D$ obtained with isopropyl alcohol were larger than those with ethanol. In principle, these experimental findings should be related to the nature of the reactants (TTIP is hydrolysed more easily than DIPBAT and isopropyl alcohol is less polar than ethanol). However, we are still looking for a convincing explanation for our results.

According to the XRD analyses, TTIP-isopropyl alcohol-Pt should be the combination with the highest photocatalytic activity, because the formation of highly crystallised anatase with larger $D$ might facilitate the transfer of photoelectrons, which could lower the probability of the recombination of photoinduced electrons and holes. However, as we shall see in the next section, this synthesis combination also led to small specific surface areas.

\subsection{BET analysis}

The specific surface area $\left(\mathrm{m}^{2} / \mathrm{g}\right)$ is a parameter commonly used to determine the type and properties of a material regarding adsorption, heterogeneous catalysis and surface reactions. Several methods have been developed to measure the specific surface area of materials; the BET $\mathrm{N}_{2}$ adsorption procedure is one of the most widely used. In this work, we used the BET method to determine the specific surface areas of the catalysts.

The synthesised $\mathrm{Pt} / \mathrm{TiO}_{2}$ catalysts displayed type-IV adsorption isotherms with one hysteresis loop at a relative pressure range of $0.5-0.8$. The measured specific surface areas for the catalysts are listed in Table 3 . The samples synthesised from TTIP possessed smaller average surface areas than those obtained from DIPBAT. With respect to the alcohol used in the catalyst synthesis, the results depend on the Ti precursor. The surface area results are undoubtedly related to the crystallinity of the synthesised catalysts. Thus, samples with high crystallinity, such as those synthesised from TTIP and isopropyl alcohol show smaller surface areas (Table 3). In contrast, materials with poor crystallinity (like the catalysts obtained using DIPBAT) display increased porosity and surface area. Similar findings have been reported in the literature for other nanoparticles synthesised in supercritical $\mathrm{CO}_{2}[33,50]$. Although it is not shown in Table 3, a slight decrease $(<5 \%)$ in specific surface area with increasing Pt loading was observed for all precursor/alcohol combinations. This finding may be related to the deposition of $\mathrm{Pt}^{0}$ nanoparticles [26].

The mean pore size in the catalysts was estimated using the Barrett-Joyner-Halenda model, while the Harkins-Jura equation was used to determine the thickness of the adsorbed $\mathrm{N}_{2}$ layer from the adsorption data assuming cylindrical pore geometry. As shown in Table 3, all samples had mesoporous structures, which can enhance the rate of gaseous photocatalytic reactions because of the rapid diffusion of gas molecules within mesopores. According to the above results, if only surface area and pore volume are taken into account, the ideal particles for photocatalysis should be those obtained from the combinations of TTIP-ethanol-Pt and DIPBAT-isopropyl alcohol-Pt.

\subsection{DRUV-vis analysis}

The DRUV-vis spectra of the synthesised catalysts generally shifted toward the visible range compared with that of the reference commercial catalyst (Fig. 8). These results are of great interest because the emission spectrum of the Xe lamp used in the photocatalytic experiments to mimic the solar spectrum exhibited high irradiance in the visible range. The reason for using this lamp was to gauge the possibility of using sunlight as the energy source in future research.

Many groups have examined how loading $\mathrm{TiO}_{2}$ with different cations shifts its absorption into the visible region [16-18]. The metal atoms act as a sink for photoexcited electrons, which enhances charge separation efficiency [51]. This increase in visible-light absorption is also associated with the formation of oxygen vacancies/ $\mathrm{Ti}^{3+}$ species [11]. In this study, the absorbance in the visible range increased by up to ten times for TTIP-ethanol-Pt (Fig. 8(b)), DIPBAT-isopropyl alcohol-Pt (Fig. 8(c)) and DIPBAT-ethanol-Pt (Fig. 8(d)) compared with that of the commercial catalyst. In the case of TTIP-isopropyl alcohol-Pt, visible light absorption increased by seven times (Fig. 8(a)).

Regarding the effect of the Pt loading percentage in the catalyst, Fig. 8 reveals that the absorbance in the visible range is higher for the $\mathrm{Pt} / \mathrm{TiO}_{2}$ catalysts than for commercial $\mathrm{TiO}_{2}$. Moreover, the absorbance intensity increased with the metal concentration for catalysts synthesized with both Ti precursors [26]. Absorption thresholds and $E_{\mathrm{g}}$ of the synthesised catalysts were calculated from the UV-vis spectra in Fig. 8, and are presented in Table 4. Each absorption threshold was obtained from the intersection of the $\mathrm{x}$-axis and a line tangent to the absorption curve where the maximum slope is found [52]. A shift towards the visible region of the absorption threshold of met- 

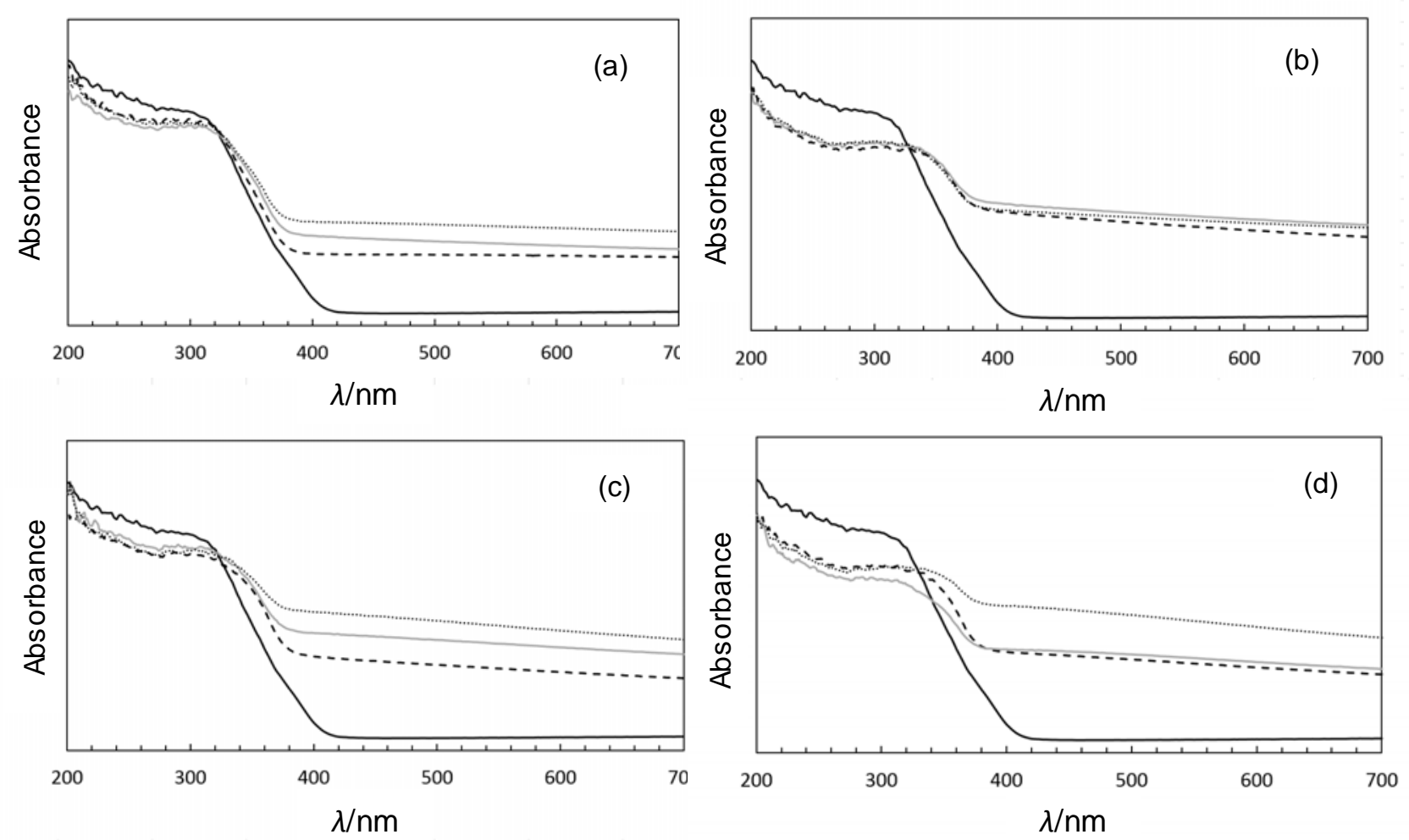

Fig. 8. DRUV-vis spectra of commercial and synthesised catalysts. (a) TTIP-isopropyl alcohol-Pt; (b) TTIP-ethanol-Pt; (c) DIPBAT-isopropyl alcohol-Pt (d) DIPBAT-ethanol-Pt (black lines: commercial, dashed lines $1 \% \mathrm{Pt}$, grey lines $2 \% \mathrm{Pt}$, dotted lines $3 \% \mathrm{Pt}$ ).

$\mathrm{al} / \mathrm{TiO}_{2}$ photocatalysts has been often taken as direct evidence for enhancement of their photocatalytic activity under solar or visible irradiation [52].

The band gap is the void region that extends from the top of the filled valence band to the bottom of the vacant conduction band in a semiconductor [53]. The band gap of a semiconductor catalyst defines the amount of photons that are available for quantum conversion. $E_{\mathrm{g}}$ can be calculated from equation 2, where $h$ is the Planck constant $\left(4.13566733 \times 10^{-15} \mathrm{eV} \cdot \mathrm{s}\right), c$ is the speed of light $\left(3 \times 10^{5} \mathrm{~km} / \mathrm{s}\right)$ and $\lambda$ is absorption threshold (nm) [54].

Table 4

Absorption threshold and band gap energies of commercial and synthesised catalysts.

\begin{tabular}{lcc}
\hline Catalyst & $\begin{array}{c}\text { Absorption threshold } \\
(\mathrm{nm})\end{array}$ & $\begin{array}{c}\text { Band gap } \\
(\mathrm{eV})\end{array}$ \\
\hline P-25 & 407 & 3.048 \\
TTIP-isopropyl alcohol-1\%Pt & 415 & 2.990 \\
TTIP-isopropyl alcohol-2\%Pt & 427 & 2.906 \\
TTIP-isopropyl alcohol-3\%Pt & 436 & 2.846 \\
TTIP-ethanol-1\%Pt & 453 & 2.739 \\
TTIP-ethanol-2\%Pt & 457 & 2.715 \\
TTIP-ethanol-3\%Pt & 457 & 2.715 \\
DIPBAT-isopropyl alcohol-1\%Pt & 416 & 2.982 \\
DIPBAT-isopropyl alcohol-2\%Pt & 430 & 2.885 \\
DIPBAT-isopropyl alcohol-3\%Pt & 471 & 2.834 \\
DIPBAT-ethanol-1\%Pt & 426 & 2.812 \\
DIPBAT-ethanol-2\%Pt & 447 & 2.776 \\
DIPBAT-ethanol-3\%Pt & 483 & 2.669 \\
\hline
\end{tabular}

$$
E_{\mathrm{g}}=\frac{h \cdot c}{\lambda}
$$

The absorption threshold of the commercial catalyst was $407 \mathrm{~nm}$, whereas those of the synthesised catalysts were higher (415-483 nm) (Table 4). The combination that gave the highest mean value was TTIP-ethanol-Pt, even though DIPBAT-ethanol-3\%Pt displayed the highest individual value. The absorbance intensity in the visible range is reflected by the colour of the samples. Thus, as shown in Fig. 9, the samples with weak absorbance in the visible range (P-25) are white, those with a moderate absorbance are grey (TTIP-isopropyl alcohol-1\%Pt), and those with the strongest visible absorption (TTIP-ethanol-1\%Pt) are brown. It should be noted that Fig. 9 depicts the photographs of the catalysts after use in the photocatalytic reaction, although their colour was similar before reaction. Another interesting observation in Fig. 8 is that only one absorption edge can be detected in the DRUV-vis spectra, indicating that the catalysts behave as a single phase rather than a mixture of compounds with different absorption thresholds [52]. Moreover, there is a linear correlation between the absorption threshold and the amount of Pt in the catalysts.

Similarly, while $E_{\mathrm{g}}$ of the commercial catalyst was $3.048 \mathrm{eV}$ (pure anatase: $3.2 \mathrm{eV}$ ), all the synthesised catalysts showed $E_{\mathrm{g}}$ in the range of $2.669-2.990 \mathrm{eV}$. This means that the energy required to excite the synthesised catalysts is lowered because extra levels are introduced in the gap region below the conduction band of $\mathrm{TiO}_{2}[6,15]$. This decrease in excitation energy 

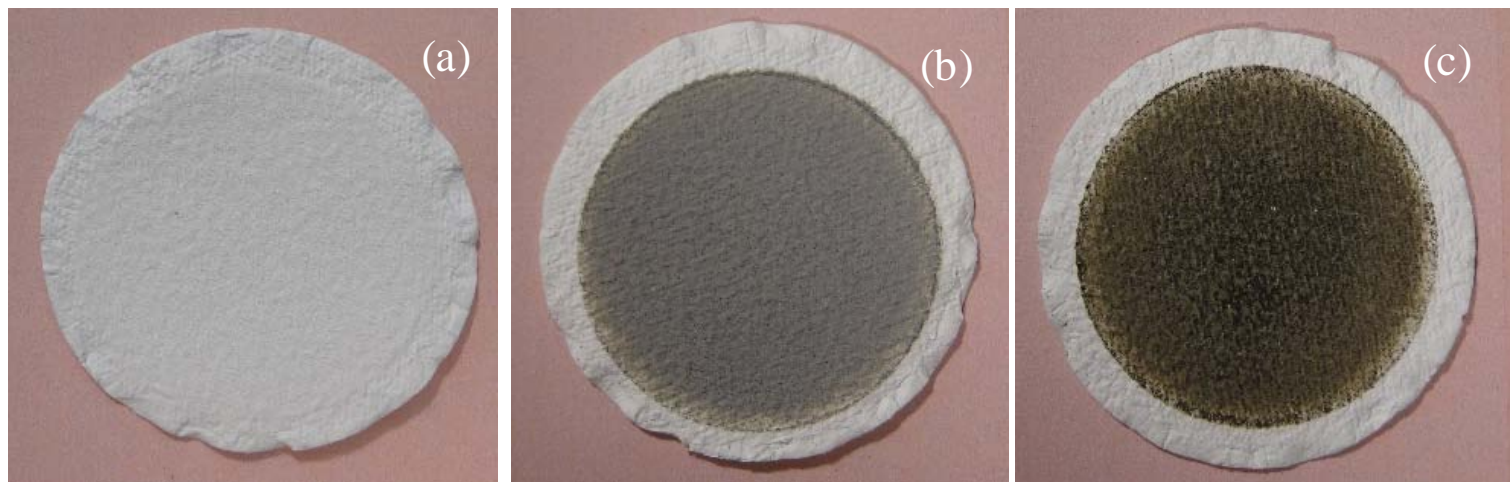

Fig. 9. Photographs of filters with catalysts after photocatalytic experiments.

(a) Commercial;

(b) TTIP-isopropyl alcohol-1\%Pt;

(c)

TTIP-ethanol-1\%Pt.

allows more efficient use of the visible spectrum by the $\mathrm{Pt} / \mathrm{TiO}_{2}$ catalysts $[15,55]$.

Notably, the combinations with the lowest mean band gap value are TTIP-ethanol-Pt $(2.723 \mathrm{eV})$ and DIPBAT-ethanol-Pt $(2.752 \mathrm{eV})$. This variable decreased less than $5 \%$ as Pt loading increased from 1 to $3 \mathrm{wt} \%$. For this reason, all the photocatalytic experiments were performed using catalysts with a Pt loading of $1 \mathrm{wt} \%$. If these results are compared with those from catalysts synthesised in the absence of Pt [45], the adsorption threshold and $E_{\mathrm{g}}$ of every $\mathrm{Pt} / \mathrm{TiO}_{2}$ catalyst are higher and smaller, respectively, than those of the corresponding catalyst without Pt. Thus, the introduction of Pt has a positive influence on the light harvesting ability of $\mathrm{TiO}_{2}$. In short, the absorbance of the synthesised catalysts is increased in the visible range compared with that of P-25, especially when ethanol is used as the hydrolysis agent.

\subsection{FTIR analysis}

The FTIR spectrum of the commercial P-25 catalyst (Fig. 10) only shows a peak around $690 \mathrm{~cm}^{-1}$, which corresponds to Ti-O-Ti bonds [56].

The FTIR spectra of the synthesised catalysts are generally similar to that of the commercial catalyst (Figure 10). Some of the catalysts show a small peak around $1625 \mathrm{~cm}^{-1}$ and/or a wide band centred at $3000 \mathrm{~cm}^{-1}$, which are attributed to stretching vibrations of $\mathrm{OH}$ groups and $\mathrm{H}_{2} \mathrm{O}$ on the catalyst surface $[57,58]$. In principle, as explained above, the presence of these species usually favours the photocatalytic process [18]. The presence of $\mathrm{OH}$ groups (Brønsted acid sites) is beneficial for the reduction of $\mathrm{CO}_{2}$, because they lead to efficient charge separation and transfer to the $\mathrm{TiO}_{2}$ surface [11]. The abovementioned peaks mainly appear in catalysts that use ethanol as the hydrolysis agent, especially the combination TTIP-ethanol-Pt. In the case of DIPBAT-ethanol-Pt, these peaks disappear when the Pt content exceeds $1 \mathrm{wt} \%$.

\subsection{Particle size and particle size distribution}

Particle size distribution and mean particle size are two important parameters of particulate materials. Both variables have a strong influence on other previously mentioned parameters such as surface area and porosity $[33,38,50]$, which determine the efficiency of photocatalysis because they provide a contacting surface between catalyst, light and reactants.

Regarding mean particle size, the mean size of the commercial catalyst $(3 \mu \mathrm{m})$ is considerably smaller than those of the synthesised catalysts; for example, $8.75 \mu \mathrm{m}$ for TTIP-ethanol-1\%Pt. These results are in accordance with the SEM images of the synthesised catalysts. The particle size distributions of the synthesised catalysts are wide; only $50 \%$ of particles are around $5 \mu \mathrm{m}$ in size, whereas the commercial catalyst has $72 \%$ of particles with sizes in the range from $0.6-5$ $\mu \mathrm{m}$.

Considering the effects of the reagents used on particle size, the influence of both precursors on particle size is smaller than those of the alcohol employed and metal loading. Thus, the introduction of ethanol and a larger amount of Pt facilitate increased particle sizes and aggregation, as indicated in SEM measurements. These results agree with those reported by Alonso et al. [33]. Decreasing particle size leads to increased surface energy, lattice distortion/strain and changed surface dangling bond population, which means that $\mathrm{TiO}_{2}$ surface properties improve as particle size decreases [18]. In other words, if only surface properties are considered, the commercial catalyst should show higher photocatalytic activity than the synthesised catalysts.

\subsection{Photocatalytic activity in $\mathrm{CO}_{2}$ reduction}

The majority of photocatalytic $\mathrm{CO}_{2}$ reduction studies have been performed in liquid media using $\mathrm{H}_{2} \mathrm{O}$ as the solvent. However, one important issue when studying this process is the physical state in which it is carried out. For example, although $\mathrm{CO}_{2}$ photoreduction in liquid $\mathrm{H}_{2} \mathrm{O}$ is relatively simple, certain problems arise because of both the low solubility of $\mathrm{CO}_{2}$ in $\mathrm{H}_{2} \mathrm{O}$ and the existence of competing reactions that consume holes and electrons, leading to the formation of $\mathrm{H}_{2}$ and $\mathrm{H}_{2} \mathrm{O}_{2}$ at the expense of $\mathrm{CO}_{2}$ reduction products (methanol, $\mathrm{CH}_{4}, \mathrm{CO}$, etc.) [59]. Furthermore, if $\mathrm{CO}_{2}$ reduction is performed in liquid $\mathrm{H}_{2} \mathrm{O}$, $\mathrm{CO}_{2}$ is in the form of carbonates or bicarbonates, which are more difficult to reduce than $\mathrm{CO}_{2}$ itself [6]. Thus, it has been 

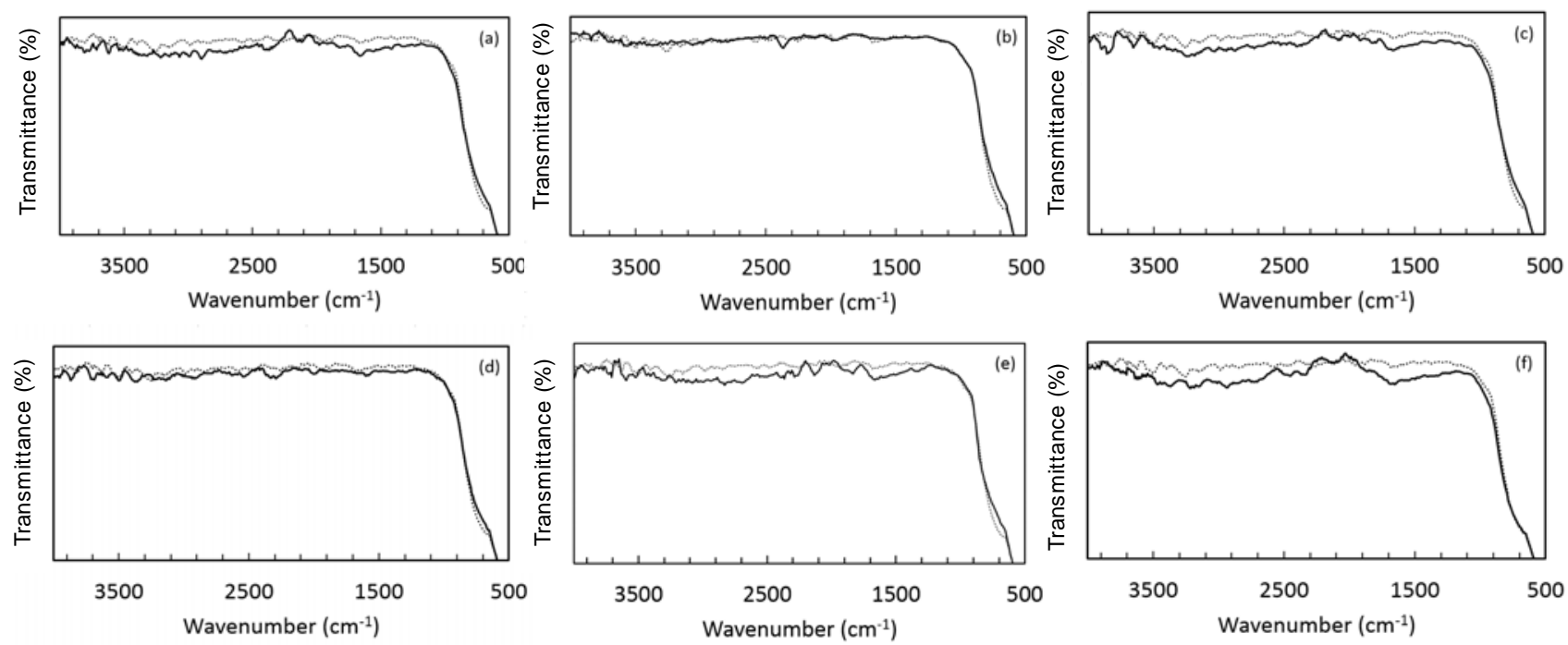

Fig. 10. FTIR spectra of synthesised catalysts (solid lines) and P-25 (dotted lines). (a) TTIP-ethanol-1\%Pt; (b) TTIP-isopropyl alcohol-1\%Pt; (c) TTIP-ethanol-2\%Pt; (d) DIPBAT-isopropyl alcohol-1\%Pt; (e) TTIP-ethanol-3\%Pt; (f) DIPBAT-ethanol-1\%Pt.

found that when liquid $\mathrm{H}_{2} \mathrm{O}$ is used as the reaction medium, organic yields are low [59]. To avoid such liquid-phase reaction problems, some authors have proposed working under gas-phase conditions [35,55]. Moreover, this would provide an additional advantage because in the reactions with $\mathrm{H}_{2} \mathrm{O}$ vapour, the photocatalyst is immobilised, which simplifies the separation of products from the catalyst. For all these reasons, we decided to test the activity of the synthesised catalysts by performing $\mathrm{CO}_{2}$ photoreduction in the gas phase. Different series of blank experiments ( $(\mathrm{a})$ : in the absence of photocatalyst, (b): in the dark and (c): only with wet He (in the absence of $\mathrm{CO}_{2}$ )) were performed, after which no reaction product containing $\mathrm{C}$ was detected, except for $\mathrm{CO}_{2}$ in series (a) and (b) (data not shown). Table 5 presents the results obtained with commercial and synthesised catalysts in the presence of light and $\mathrm{CO}_{2}$.

Table 5 reveals that the main reaction products were $\mathrm{CH}_{4}$ and $\mathrm{CO}$, a result consistent with one of the popular possible reduction mechanisms described in the literature [49] and with experimental results from other authors. For example, Yui et al. [60] reported that the main product from $\mathrm{CO}_{2}$ photoconversion was $\mathrm{CO}$ and that substantial quantities of $\mathrm{CH}_{4}$ were obtained only after introducing a metal onto $\mathrm{TiO}_{2}$. Mao et al. [44] later confirmed this finding, reporting that $\mathrm{CH}_{4}$ was the main conversion product of $\mathrm{CO}_{2}$ photoreduction using Pt dispersed on $\mathrm{TiO}_{2}$ as a catalyst.

Four preliminary tests were carried out with commercial $\mathrm{P}-25$ as the catalyst to select the operating conditions (amount of catalyst and $\mathrm{H}_{2} \mathrm{O}$ vapour $/ \mathrm{CO}_{2}$ ratio) for the photocatalytic experiments with synthesised $\mathrm{Pt}$ dispersed on $\mathrm{TiO}_{2}$ catalysts (Table 5). These tests were also intended to gather data to compare the performance of commercial $\mathrm{TiO}_{2}$ and $\mathrm{Pt} / \mathrm{TiO}_{2}$ catalysts. The parameter used to assess catalyst performance was the rate of product formation. For $\mathrm{CO}_{2}$ photoreduction, this parameter is generally expressed as the amount of product ( $\mu \mathrm{mol})$ divided by the time it took to accumulate $(\mathrm{h})$ and the amount of catalyst used (g) [49]. In the assays with commercial $\mathrm{TiO}_{2}$, Table 5 shows that the $\mathrm{CH}_{4}$ and $\mathrm{CO}$ production rates were 0.033-0.078 and 1.497-2.014 $\mu \mathrm{mol} \mathrm{g} \mathrm{g}^{-1} \mathrm{~h}^{-1}$, respectively. The activity of P-25 may be attributed to the complementary effects of anatase and rutile phases, in which the interfaces between the phases could play a major role in catalysis [49].

The effect of $\mathrm{H}_{2} \mathrm{O}$ vapour/ $\mathrm{CO}_{2}$ ratio on photocatalyst activity was investigated using about $35 \mathrm{~g}$ of $\mathrm{TiO}_{2}$ and $\mathrm{H}_{2} \mathrm{O}$ vapour $/ \mathrm{CO}_{2}$ ratios of 2:1, 2:7 and 2:20. Table 5 reveals that the highest total

Table 5

Results for photocatalytic reduction of $\mathrm{CO}_{2}$.

\begin{tabular}{|c|c|c|c|c|c|}
\hline Catalyst & Pt loading (wt\%) & $\begin{array}{l}\text { Catalyst weight } \\
\text { (mg) }\end{array}$ & $\begin{array}{c}\mathrm{H}_{2} \mathrm{O} / \mathrm{CO}_{2} \\
(\mathrm{~mol} / \mathrm{mol})\end{array}$ & $\begin{array}{l}\text { Reaction time } \\
\text { (h) }\end{array}$ & $\begin{array}{c}\text { Production rates } \\
\left(\mu \mathrm{mol} \mathrm{g}^{-1} \mathrm{~h}^{-1}\right) \mathrm{CH}_{4}(\mathrm{CO})\end{array}$ \\
\hline $\mathrm{P}-25$ & 0 & 35.6 & $2 / 1$ & 3 & $0.033(1.497)$ \\
\hline P-25 & 0 & 35.5 & $2 / 7$ & 3 & $0.075(2.014)$ \\
\hline P-25 & 0 & 35.2 & $2 / 20$ & 3 & $0.078(1.875)$ \\
\hline P-25 & 0 & 75.5 & $2 / 7$ & 3 & $0.033(1.887)$ \\
\hline TTIP-isopropyl alcohol & 1 & 34.6 & $2 / 7$ & 3 & $0.135(0.109)$ \\
\hline TTIP-ethanol & 1 & 39.6 & $2 / 7$ & 3 & $0.245(0.058)$ \\
\hline DIPBAT-isopropyl alcohol & 1 & 35.7 & $2 / 7$ & 3 & $0.164(0.132)$ \\
\hline DIPBAT-isopropyl alcohol & 1 & 36.9 & $2 / 7$ & 4 & $0.172(0.096)$ \\
\hline DIPBAT-ethanol & 1 & 39.3 & $2 / 7$ & 3 & $0.140(0.167)$ \\
\hline DIPBAT-ethanol & 1 & 37.1 & $2 / 7$ & 4 & $0.131(0.069)$ \\
\hline
\end{tabular}

Light source: Xe arc lamp (450 W). 


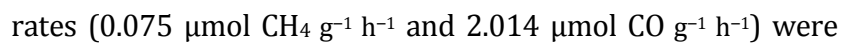
obtained at the intermediate ratio (2:7). This result agrees with those reported in the literature because, although it is commonly believed that $\mathrm{CO}_{2}$ reactivity increases as the proportion of $\mathrm{H}_{2} \mathrm{O}$ is raised, it has also been reported that excess $\mathrm{H}_{2} \mathrm{O}$ could inhibit the reaction [61]. The optimum $\mathrm{H}_{2} \mathrm{O} / \mathrm{CO}_{2}$ ratio obtained in this work (2:7) is considerably lower than that reported by Anpo et al. [61] for $\mathrm{CO}_{2}$ photoconversion in liquid $\mathrm{H}_{2} \mathrm{O}$ (5:1). This result is very interesting because it indicates that the reaction products are far less dilute when the photoreduction process is performed in the gas phase (i.e., using $\mathrm{H}_{2} \mathrm{O}$ vapour instead of liquid $\mathrm{H}_{2} \mathrm{O}$ ).

Considering the effect of catalyst weight, the experiments performed at a $\mathrm{H}_{2} \mathrm{O} / \mathrm{CO}_{2}$ ratio of 2:7 with a greater weight of catalyst (75.5 g vs. $35.5 \mathrm{~g}$ ) did not necessarily lead to the best photocatalytic performance. This may be explained by considering the well-known fact that formation rate increases linearly with catalyst concentration only up to a certain value at which decreased light penetration and increased scattering occur, limiting formation rate [49].

Regarding the effect of $\mathrm{Pt}$ on $\mathrm{TiO}_{2}$ photocatalytic performance, for the experiments carried out with catalyst weights of 35-40 mg, a $\mathrm{H}_{2} \mathrm{O}$ vapour $/ \mathrm{CO}_{2}$ ratio of $2: 7$ and operating times of 3-4 h, the $\mathrm{CH}_{4}$ production rates were about 3.2 times higher using the $\mathrm{Pt} / \mathrm{TiO}_{2}$ catalysts than the commercial catalyst. The highest performance was obtained for the combination TTIP-ethanol-1\%Pt when the operating time was $3 \mathrm{~h}$. It should be noted that this catalyst had already shown superior characteristics, as illustrated in Table 6, which orders the catalysts used in the photocatalytic experiments from best to worst according to the value of the property analysed. In particular, Table 6 reveals that the characteristics that make this catalyst better than the others are its morphology (polyhedral), narrow $E_{\mathrm{g}}$, the presence of surface $\mathrm{OH}$ groups, high surface area and relatively large mean pore size.

Regarding the influence of these properties of catalysts on the $\mathrm{CO}_{2}$ photocatalysis, it should be noted that the higher the surface area is, the greater the number of reactant molecules adsorbed and the more quickly the electrons can reach them. This results in a lower recombination probability and higher product yield $[10,18]$. In addition, the presence of basic species (OH groups) on the catalyst surface leads to stronger interactions with $\mathrm{CO}_{2}$ and higher uptake of this gas $[10,11,18]$, so the larger the surface area is, the higher the catalyst activity will be.

Table 6

Ordering of catalysts used in photocatalytic tests.

\begin{tabular}{lcc}
\hline Catalyst property & Desired value & Ordering of catalysts \\
\hline Photocatalytic activity & High & $\mathrm{A}>\mathrm{B}>\mathrm{C}>\mathrm{D}$ \\
Particle size & Small & $\mathrm{D}>\mathrm{A}>\mathrm{B}>\mathrm{C}$ \\
Morphology & Polyhedral & $\mathrm{A}>\mathrm{D}>\mathrm{C}>\mathrm{B}$ \\
Crystallinity & High & $\mathrm{D}>\mathrm{B}>\mathrm{A}>\mathrm{C}$ \\
Band gap energy & Low & $\mathrm{A}>\mathrm{C}>\mathrm{B}>\mathrm{D}$ \\
Presence of surface OH groups & High & $\mathrm{A}>\mathrm{C}>\mathrm{B}>\mathrm{D}$ \\
Surface area & High & $\mathrm{A}>\mathrm{B}>\mathrm{C}>\mathrm{D}$ \\
Mean pore size & High & $\mathrm{D}>\mathrm{A}>\mathrm{B}>\mathrm{C}$
\end{tabular}

A: TTIP-ethanol-1\%Pt; B: DIPBAT-isopropyl alcohol-1\%Pt; C: DIPBAT -ethanol-1\%Pt; D: TTIP-isopropyl alcohol-1\%Pt.
Regarding mean pore size, although small pores result in a large surface area, mesopores (as in our case: 7-10 nm) are always preferable to allow diffusion of reactant and product molecules [18]. A narrow $E_{\mathrm{g}}$ is also desired because it improves light absorption and charge carrier generation [7-10,62]. Finally, polyhedral particle shapes show higher activity than rounded particles because of their higher density of catalytically active sites, although this has not yet been fully explained [41].

The catalyst showing the second highest $\mathrm{CH}_{4}$ production rate was DIPBAT-isopropyl alcohol-1\%Pt, which also exhibited high surface area. Alonso and colleagues also obtained good results with this catalyst in the oxidation of methyl orange in aqueous solutions [38]. According to our results, surface area seems to be the most influential property on the catalyst activity in reduction of $\mathrm{CO}_{2}$ to fuel molecules. This assertion is further supported by the fact that the catalyst exhibiting favourable values of other properties (TTIP-isopropyl alcohol-1\%Pt), like small particle size and high crystallinity (Table 6), did not display a high $\mathrm{CH}_{4}$ production rate.

These results also clearly show that the addition of Pt to the $\mathrm{TiO}_{2}$ catalyst markedly improves the photoactivity of the resulting catalyst in $\mathrm{CH}_{4}$ production $[44,60]$. If the photocatalytic activities of $\mathrm{Pt} / \mathrm{TiO}_{2}$ are compared with those of $\mathrm{TiO}_{2}$ photocatalysts obtained from the same Ti precursors and hydrolysis agents under the same synthesis conditions in supercritical $\mathrm{CO}_{2}$ [45], we can see that there is an increase in $\mathrm{CH}_{4} / \mathrm{CO}$ ratio for the $\mathrm{Pt} / \mathrm{TiO}_{2}$ catalysts $(0.84-4.22)$ compared with those of their counterparts lacking Pt (0.03-0.30) (Table 7).

The CO production rate of the synthesised catalysts was about $90 \%$ lower than that of the commercial catalyst, even that of the synthesized catalyst with the highest CO formation rate (DIPBAT-ethanol-1\%Pt). This observation cannot be explained only by the increase in the production of $\mathrm{CH}_{4}$. The photochemical $\mathrm{H}_{2} \mathrm{O}$-gas shift reaction to produce $\mathrm{H}_{2}$ and $\mathrm{CO}_{2}$ from $\mathrm{CO}$ and $\mathrm{H}_{2} \mathrm{O}$ may have occurred, lowering the yield of $\mathrm{CO}$ [60]. This reaction is often observed in the presence of noble met$\mathrm{al} / \mathrm{TiO}_{2}$ catalysts $[60,63]$. However, this does not seem a satisfactory explanation in these experiments given the low $\mathrm{H}_{2} \mathrm{O}$ vapour $/ \mathrm{CO}_{2}$ ratio used [36]. Regarding the reaction time, Table 5 reveals that extending the photocatalytic reaction from 3 to 4 $\mathrm{h}$ did not substantially increase the $\mathrm{CH}_{4}$ production rate. According to Habisreutinger et al. [49], this saturation of the product formation curve may be caused by strong adsorption of the $\mathrm{O}_{2}$ produced in $\mathrm{CO}_{2}$ photolysis, which may block reaction sites.

Table 8 compares $\mathrm{CH}_{4}$ and $\mathrm{CO}$ production rates reported in recent studies for photocatalytic reduction of $\mathrm{CO}_{2}$ with $\mathrm{H}_{2} \mathrm{O}$ vapour as the reducing agent. The values are scarcely comparable because of the many variables are involved in the $\mathrm{CO}_{2}$ reduction process. Generally, the $\mathrm{CH}_{4}$ production rates obtained in this work are of the order of those reported for metal dispersed on $\mathrm{TiO}_{2}$ particles, $\mathrm{TiO}_{2}$ in the absence of metal, $\mathrm{TiO}_{2}$ nanotubes and even metal/ $\mathrm{TiO}_{2}$ over optical fibres.

Nevertheless, we are aware that there is still room for improvement. On the one hand, some investigators have reported higher $\mathrm{CH}_{4}$ production rates $[7,8,11,13,14,70]$; on the other 
Table 7

Comparison of the photocatalytic activities of synthesised catalysts with and without $\mathrm{Pt}$.

\begin{tabular}{|c|c|c|c|c|c|}
\hline Catalyst & Pt loading (wt\%) & Catalyst weight (mg) & $\mathrm{H}_{2} \mathrm{O} / \mathrm{CO}_{2}(\mathrm{~mol} / \mathrm{mol})$ & Reaction time (h) & $\mathrm{CH}_{4} / \mathrm{CO}(\mathrm{mol} / \mathrm{mol})$ \\
\hline P-25 & 0 & 35.5 & $2 / 7$ & 3 & 0.04 \\
\hline TTIP-isopropyl alcohol & 1 & 34.6 & $2 / 7$ & 3 & 1.24 \\
\hline TTIP-ethanol & 1 & 39.6 & $2 / 7$ & 3 & 4.22 \\
\hline DIPBAT-isopropyl alcohol & 1 & 35.7 & $2 / 7$ & 3 & 1.24 \\
\hline DIPBAT-ethanol & 1 & 39.3 & $2 / 7$ & 3 & 0.84 \\
\hline TTIP-isopropyl alcohol & 0 & 41.3 & $2 / 7$ & 3 & 0.03 \\
\hline TTIP-ethanol & 0 & 31.9 & $2 / 7$ & 3 & 0.16 \\
\hline DIPBAT-isopropyl alcohol & 0 & 28.9 & $2 / 7$ & 3 & 0.30 \\
\hline DIPBAT-ethanol & 0 & 42.0 & $2 / 7$ & 3 & 0.26 \\
\hline
\end{tabular}

Table 8

Summary of reported $\mathrm{CH}_{4}$ and $\mathrm{CO}$ production rates.

\begin{tabular}{|c|c|c|c|c|c|}
\hline Catalyst & Metal & Reagent & Light source & $\begin{array}{l}\text { Production rates }\left(\mu \mathrm{mol} \mathrm{g}^{-1} \mathrm{~h}^{-1}\right) \\
\mathrm{CH}_{4}(\mathrm{CO})\end{array}$ & Ref. \\
\hline $\mathrm{TiO}_{2}$ anchored on Vycor glass & - & $\begin{array}{l}\mathrm{CO}_{2} \\
\mathrm{H}_{2} \mathrm{O}\end{array}$ & 75 W Hg lamp & 0.11 & [64] \\
\hline $\begin{array}{l}\text { Quartz wool immersed in P-25 } \\
\text { suspension }\end{array}$ & - & $\begin{array}{l}\mathrm{CO}_{2} \\
\mathrm{H}_{2} \mathrm{O}\end{array}$ & UV lamp & $0.1(<0.1)$ & [65] \\
\hline $\mathrm{TiO}_{2}$ pellets & - & $\begin{array}{l}\mathrm{CO}_{2} \\
\mathrm{H}_{2} \mathrm{O}\end{array}$ & 3 germicidal UVC lamps ( $4.8 \mathrm{~W}), 24 \mathrm{~h}$ & $0.22(<0.16)$ & [66] \\
\hline $\mathrm{TiO}_{2}$ on glass beads & $0.25 \mathrm{wt} \% \mathrm{Pt}$ & $\begin{array}{l}\mathrm{CO}_{2} \\
\mathrm{H}_{2} \mathrm{O}\end{array}$ & $75 \mathrm{~W}$ daylight lamp & 0.3 & [67] \\
\hline P-25 & - & $\begin{array}{l}\mathrm{CO}_{2} \\
\mathrm{H}_{2} \mathrm{O}\end{array}$ & $100 \mathrm{~W}$ high pressure Hg lamp & 0.2 & [55] \\
\hline $\mathrm{TiO}_{2}-\mathrm{SiO}_{2}$-acac/optical fiber & 0.5 wt $\% \mathrm{Cu}-0.5$ wt $\% \mathrm{Fe}$ & $\begin{array}{l}\mathrm{CO}_{2} \\
\mathrm{H}_{2} \mathrm{O}\end{array}$ & Sunlight & 0.279 & {$[68]$} \\
\hline Titania nanotubes & - & $\begin{array}{l}\mathrm{CO}_{2} \\
\mathrm{H}_{2} \mathrm{O}\end{array}$ & $100 \mathrm{~W}$ high pressure Hg lamp & 0.3 & [69] \\
\hline
\end{tabular}

hand, actual conversion efficiencies reported here and in previous studies are still quite low and should be increased by orders of magnitude before the $\mathrm{CO}_{2}$ photoreduction process can be used in practical applications. Because of this, we are currently attempting to further enhance the photocatalytic activity of the $\mathrm{TiO}_{2}$-based materials reported in this work.

Specifically, to increase the selectivity of the catalysts for the productions of $\mathrm{CH}_{4}$ and methanol, three strategies are being followed: The use of $\mathrm{TiO}_{2}$-based catalysts with enhanced geometries: $\mathrm{TiO}_{2}$ nanofibres and $\mathrm{TiO}_{2}$ nanotubes with and without metal modification $[7,13]$. The addition of non-metal elements to $\mathrm{TiO}_{2}$ [8]. The synthesis of composite photocatalysts combining $\mathrm{TiO}_{2}$ and reduced graphene oxide $[9,10]$.

\section{Conclusions}

Photocatalysts with similar or better features, like high surface area, large pore volume, high crystallisation degree and high $\mathrm{OH}$ concentration, than those of commercial $\mathrm{TiO}_{2}$ can be obtained by supercritical media synthesis. This method is more environmentally friendly and scalable than traditional techniques used to fabricate $\mathrm{TiO}_{2}$-based photocatalysts. In addition, it is possible to improve the performance of catalysts by shifting their absorption spectra to the visible region if they are loaded with Pt at concentrations between 1 and 3 wt.\%.

When the synthesised catalysts were used in $\mathrm{CO}_{2}$ photoreduction in the gas phase, we detected $\mathrm{CH}_{4}$ and $\mathrm{CO}$ as the main products at the end of the reaction time, which is in agreement with one of the possible reduction mechanisms described in the literature. The $\mathrm{CH}_{4}$ production rates of the catalysts synthesised in this work were clearly improved compared with that of a commercial catalyst and better or similar to those reported in the literature for catalysts synthesised with more expensive and laborious procedures.

To sum up, photochemical conversion of $\mathrm{CO}_{2}$ constitutes not only an innovative technique to reduce greenhouse gas emission, but also a potential alternative to the depletion of fossil fuel resources. Although it is clear that the catalysts synthesised to date for $\mathrm{CO}_{2}$ reduction to fuel cannot yet be commercially applied, we expect that further developments will allow them to be in the near future. To achieve this goal, further work on photocatalyst design must combine the improvement in solar light response with the control of the efficiency and selectivity of the $\mathrm{CO}_{2}$ photoreduction process.

\section{References}

[1] Intergovernmental Panel on Climate Change (IPCC), Working Group I Contribution to the IPCC Fifth Assessment Report Climate Change 2013: The Physical Science Basis. Technical Summary, 2013 (http://www.climatechange2013.org/images/report/ WG1AR5_ALL_FINAL.pdf).

[2] S. Chakravarti, A. Gupta, U.S. Patent 6165 433, 2000.

[3] O. Zelayandia, WO Patent W02007022595 A1, 2007.

[4] O. K. Varghese, M. Paulose, T. J. LaTempa, C. A. Grimes, Nano Lett., 2009, 9, 731-737.

[5] S. C. Roy, O. K. Varghese, M. Paulose, C. A. Grimes, ACS Nano, 2010, 


\section{Graphical Abstract}

Chin. J. Catal., 2017, 38: 636-650 doi: 10.1016/S1872-2067(17)62766-9

Supercritical synthesis of platinum-modified titanium dioxide for solar fuel production from carbon dioxide

Susana Tostón, Rafael Camarillo*, Fabiola Martínez, Carlos Jiménez, Jesusa Rincón

University of Castilla-La Mancha, Spain

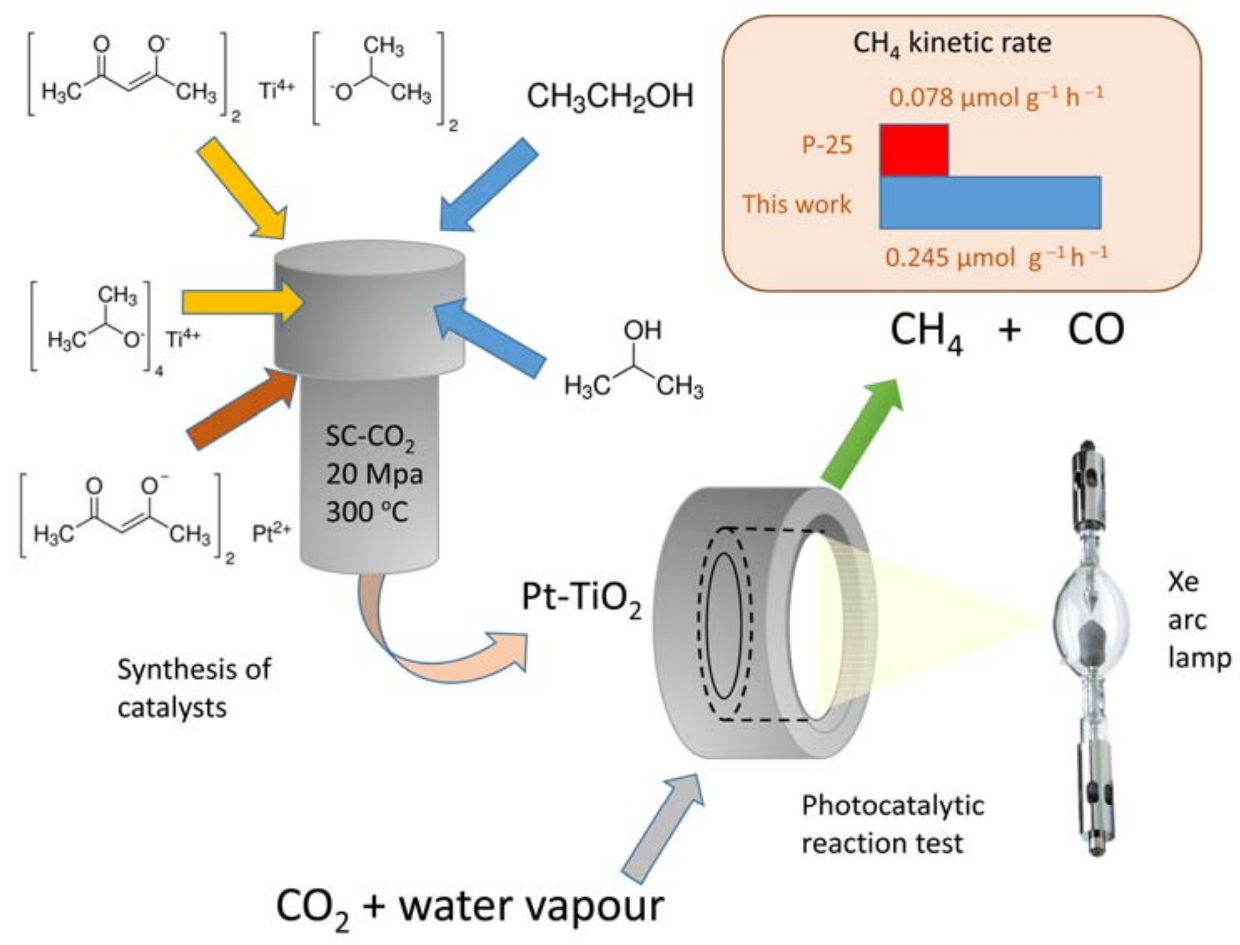

The catalytic properties of $\mathrm{Pt} / \mathrm{TiO}_{2}$ particles can be tuned by simply changing operating parameters like the type of titania precursor and/or hydrolysis agent when their hydrothermal formation reaction is accomplished in supercritical $\mathrm{CO}_{2}$. The synthesised particles exhibit superior performance to that of a commercial catalyst in the photocatalytic reduction of $\mathrm{CO}_{2}$ to methane.

4, 1259-1278.

[6] S. Neatu, J. A. Maciá-Agulló, H. Garcia, Int. J. Mol. Sci., 2014, 15, 5246-5262.

[7] Y. F. Li, W. P. Zhang, X. Shen, P. F. Peng, L. B. Xiong, Y. Yu, Chin. J. Catal., 2015, 36, 2229-2236.

[8] M. S. Akple, J. X. Low, Z. Y. Qin, S. Wageh, A. A. Al-Ghamdi, J. G. Yu, S. Liu, Chin. J. Catal., 2015, 36, 2127-2134.

[9] L. C. Sim, K. H. Leong, P. Saravanan, S. Ibrahim, Appl. Surf. Sci., 2015, 358, 122-129.

[10] J. X. Low, B. Cheng, J. G. Yu, Appl. Surf. Sci., 2017, 392, 658-686.

[11] Z. Q. He, J. T. Tang, J. Shen, J. M. Chen, S. Song, Appl. Surf. Sci., 2016, 364, 416-427.

[12] M. Tahir, B. Tahir, N. A. S. Amin, Appl. Surf. Sci., 2015, 356, 1289-1299.

[13] P. Reñones. A. Moya, F. Fresno, L. Collado, J. J. Vilatela, V. A. de la Peña O'Shea, J. $\mathrm{CO}_{2}$ Util., 2016, 15, 24-31.

[14] J. Y. Do, V. Tamilavan, R. Agneeswari, M. H. Hyun, M. Kang, J. Photochem. Photobio. A, 2016, 330, 30-36.

[15] A. Zaleska, Recent Pat. Eng., 2008, 2,157-164.

[16] C. Ampelli, R. Passalacqua, C. Genovese, S. Perathoner, G. Centi, T. Montini, V. Gombac, J. J. Delgado Jaen, P. Fornasiero, RSC Adv., 2013, 3, 21776-21778.

[17] C. Ampelli, C. Genovese, R. Passalacqua, S. Perathoner, G. Centi, Appl. Therm. Eng., 2014, 70, 1270-1275.

[18] M. A. Henderson, Surf. Sci. Rep., 2011, 66, 185-297.
[19] Y. Ma, X. L. Wang, Y. S. Jia, X. B. Chen, H. X. Han, C. Li, Chem. Rev., 2014, 114, 9987-10043.

[20] Q. H. Zhang, W. D. Han, Y. J. Hong, J. G. Yu, Catal. Today, 2009, 148, 335-340.

[21] G. N. Kryukova, G. A. Zenkovets, A. A. Shutilov, M. Wilde, K. Günther, D. Fassler, K. Richter, Appl. Catal. B, 2007, 71, 169-176.

[22] F. Chekin, S. Bagherib, S. B. Abd Hamidb, Sensors Actuat. B, 2013, 177, 898-903.

[23] S. Semlali, T. Pigot, D. Flahaut, J. Allouche, S. Lacombe, L. Nicole, Appl. Catal. B, 2014, 150-151, 656-662.

[24] Y. Hu, X. Song, S. M. Jiang, C. H. Wei, Chem. Eng. J., 2015, 274, $102-112$.

[25] A. Ofiarska, A. Pieczyńska, A. Fiszka Borzyszkowska, P. Stepnowski, E. M. Siedlecka, Chem. Eng. J., 2016, 285, 417-427.

[26] Z. Xiong, H. B. Wang, N. Y. Xu, H. L. Li, B. Z. Fang, Y. C. Zhao, J. Y. Zhang, C. G. Zheng, Int. J. Hydrogen Energy, 2015, 40, 10049-10062.

[27] R. Pol, M. Guerrero, E. García-Lecina, A. Altube, E. Rossinyol, S. Garroni, M. D. Baró, J. Pons, J. Sort, E. Pellicer, Appl. Catal. B, 2016, $181,270-278$.

[28] H. Fernández-Rodríguez, E. Alonso, M. J. Cocero, Síntesis en medio supercrítico de materiales para su utilización en reacciones catalíticas heterogéneas, Book of abstracts Flucomp, Madrid, 2009.

[29] A. de Lucas, J. Rincón, I. Gracia, J. Am. Oil Chem. Soc., 2003, 80, 
181-188.

[30] J. Rincón, R. Camarillo, L. Rodríguez, V. Ancillo, Ind. Eng. Chem. Res., 2010, 49, 2410-2418.

[31] J. Rincón, A. De Lucas, I. Gracia, Sep. Sci. Technol., 2000, 35, 2745-2763.

[32] J. Rincón, F. Martínez, L. Rodríguez, V. Ancillo, J. Supercrit. Fluids, 2011, 56, 72-79.

[33] E. Alonso, I. Montequi, S. Lucas, M. J. Cocero, J. Supercrit. Fluids, 2007, 39, 453-461.

[34] S. Tostón, R. Camarillo, F. Martínez, C. Jiménez, J. Rincón, Res. J. Chem. Environ., 2014, 18, 46-53.

[35] D. Uner, M. M. Oymak, Catal. Today, 2012, 181, 82-88.

[36] C. J. Wang, R. L. Thomson, J. Baltrus, C. Matranga, J. Phys. Chem. Lett., 2010, 1, 48-53.

[37] N. Aman, P. K. Satapathy, T. Mishra, M. Mahato, N. N. Das, Mater. Res. Bull., 2012, 47, 179-183.

[38] E. Alonso, I. Montequi, M. J. Cocero, J. Supercrit. Fluid., 2009, 49, 233-238.

[39] G. Wu, T. Nishikawa, B. Ohtani, A. Chen, Chem. Mater., 2007, 19, $4530-4537$.

[40] Y. Shih, C. Lin, Environ. Sci. Pollut. Res., 2012, 19, 1652-1658.

[41] N. Balazs, K. Mogyorosi, D. F. Sranko, A. Pallagi, T. Alapi, A. Oszko, A. Dombi, P. Sipos, Appl. Catal. B, 2008, 84, 356-362.

[42] J. G. Yu, W. G. Wang, B. Cheng, B. L. Su, J. Phys. Chem. C, 2009, 113, 6743-6750.

[43] Q. Wang, D. Yang, D. M. Chen, Y. B. Wang, Z. Y. Jiang, J. Nanopart. Res., 2007, 9, 1087-1096.

[44] J. Mao, L. Q. Ye, K. Li, X. H. Zhang, J. Y. Liu, T. Y. Peng, L. Zan, Appl. Catal. B, 2014, 144, 855-862.

[45] R. Camarillo, S. Tostón, F. Martínez, C. Jiménez, I. Asencio, J. Rincón, J. Earth Sci. Clim. Change, 2016, 7(9), 149.

[46] R. Camarillo, J. Rincón, Chem. Eng. Technol., 2011, 34, 1675-1684.

[47] B. K. Avasarala, S. R. Tirukkovalluri, S. Bojja, Int. J. Mater. Res., 2010, 101, 1563-1571.

[48] A. L. Patterson, Phys. Rev., 1939, 56, 978-982.

[49] S. N. Habisreutinger, L. Schmidt-Mende, J. K. Stolarczyk, Angew. Chem. Int. Ed., 2013, 52, 7372-7408.

[50] E. Reverchon, G. Caputo, S. Correra, P. Cesti, J. Supercritic. Fluids,
2003, 26, 253-561.

[51] I. Tanabe, Y. Ozaki, Y., Chem. Commun., 2014, 50, 2117-2119.

[52] F. Gracia, J. P. Holgado, A. Caballero, A. R. Gonzalez-Elipe, J. Phys. Chem. B, 2004, 108, 17466-17476.

[53] A. L. Linsebigler, G. Q. Lu, J. T. Yates Jr., Chem. Rev., 1995, 95, 735-758.

[54] S. Bagwasi, B. Tian, F. Chen, J. Zhang, Appl. Surf. Sci., 2012, 258, 3927-3935.

[55] M. Kitano, M. Matsuoka, M. Ueshima, M. Anpo, Appl. Catal. A, 2007, $325,1-14$

[56] H. Zhang, X. J. Lv, Y. M. Li, Y. Wang, J. H. Li, ACS Nano, 2010, 4, 380-386.

[57] Y. Zhang, P. Zhang, Y. N. Huo, D. Q. Zhang, G. S. Li, H. X. Li, Appl. Catal. B, 2012, 115-116, 236-244.

[58] X. K. Li, Z. J. Zhang, W. Li, H. Q. Pan, Appl. Catal. A, 2012, 429-430, 31-38.

[59] P. Usubharatana, D. McMartin, A. Veawab, P. Tontiwachwuthikul, Ind. Eng. Chem. Res., 2006, 45, 2558-2568.

[60] T. Yui, A. Kan, C. Saitoh, K. Koike, T. Isubuki, O. Ishitani, ACS Appl. Mater. Interfaces, 2011, 3, 2594-2600.

[61] M. Anpo, H. Yamashita, Y. Ichihashi, S. Ehara, J. Electroanal. Chem., 1995, 396, 21-26.

[62] M. Marszewski, S. W. Cao, J. G. Yu, M. Jaroniec, Mater. Horiz., 2015, 2, 261-278.

[63] T. D. Nguyen-Phan, A. E. Barber, J. A. Rodríguez, S. D. Senanayake, Appl. Catal. A, 2016, 518, 18-47.

[64] M. Anpo, K. Chiba, J. Mol. Catal., 1992, 74, 207-212.

[65] F. Saladin, L. Forss, I. Kamber, J. Chem. Soc. Chem. Commun., 1995, 533-534.

[66] S. Sing Tan, L. Zou, E. Hu, Sci. Technol. Adv. Mater., 2007, 8, 89-92.

[67] O. Ozcan, F. Yukruk, E. U. Akkaya, D. Uner, Appl. Catal. B, 2007, 71, 291-297.

[68] T. V. Nguyen, J. C. S. Wu, Appl. Catal. A, 2008, 335, 112-120.

[69] B. K. Vijayan, N. M. Dimitrijevic, J. Wu, K. A. Gray, J. Phys. Chem. C, 2010, 114, 21262-12269.

[70] J. Pan, X. Wu, L. Z. Wang, G. Liu, G. Q. Lu, H. M. Cheng, Chem. Commun., 2011, 47, 8361-8363.

\title{
超临界合成Pt修饰的 $\mathrm{TiO}_{2}$ 用于光催化 $\mathrm{CO}_{2}$ 还原制备太阳能燃料
}

\author{
Susana Tostón, Rafael Camarillo*, Fabiola Martínez, Carlos Jiménez, Jesusa Rincón \\ 亚拉曼查大学环境科学与生物化学学院化工系, 托莱多45071, 西班牙
}

摘要: 考察了超临界条件下合成 $\mathrm{TiO}_{2}$ 基光催化剂的性质, 尤其是在超临界 $\mathrm{CO}_{2}$ 下得到的分散在 $\mathrm{TiO}_{2}$ 上 $\mathrm{Pt}$ 的特性, 并与商品化 $\mathrm{TiO}_{2}$ 性能进行了比较. 另外, 所得催化剂的光催化活性用 $\mathrm{CO}_{2}$ 光还原制太阳能燃料进行了评价. 结果表明, 该催化剂可得到 具有比商用 $\mathrm{TiO}_{2}$ 更好或类似的性能(高比表面积、结晶度、表面羟基浓度, 大的孔容、增强的可见光吸收、高的甲烷生成 速率)而用于 $\mathrm{CO}_{2}$ 还原制备燃料的反应中. 这可归因于该催化剂超临界介质合成过程.

关键词: 二氧化钛; 铂; 光催化剂; 金属分散度; 光还原二氧化碳

收稿日期: 2016-11-21. 接受日期: 2016-12-21. 出版日期: 2017-04-05.

*通讯联系人. 电子信箱: rafael.camarillo@uclm.es

基金来源：西班牙政府基金项目(CTM 2011-26564); 卡斯蒂利亚-拉曼恰地方政府基金项目(PEII10-0310-5840); 伊维尔德罗拉公

司基金资助(能源及环境研究科研基金2010/12 for Susana Tostón).

本文的英文电子版由Elsevier出版社在ScienceDirect上出版(http://www.sciencedirect.com/science/journal/18722067). 